\title{
Dysregulation of TRPV4, eNOS and caveolin-1 contribute to endothelial dysfunction in the streptozotocin rat model of diabetes
}

Yousif A Shamsaldeen ${ }^{* 1,2}$, Lisa A Lione ${ }^{1}$ and Christopher D Benham ${ }^{1}$

School of Life and Medical Sciences, University of Hertfordshire, College lane, Hatfield, Hertfordshire, AL10 9AB, UK.

Department of Pharmacy, Kuwait Hospital, Sabah Alsalem, 44001, Kuwait.

*Correspondence: yousefshamsaldeen@hotmail.com

\section{Abstract}

Endothelial dysfunction is a common complication in diabetes in which endotheliumdependent vasorelaxation is impaired. The aim of this study was to examine the involvement of the TRPV4 ion channel in type 1 diabetic endothelial dysfunction and the possible association of endothelial dysfunction with reduced expression of TRPV4, endothelial nitric oxide synthase (eNOS) and caveolin-1.

Male Wistar rats (350-450 g) were injected with $65 \mathrm{mg} / \mathrm{kg}$ i.p. streptozotocin (STZ) or vehicle. Endothelial function was investigated in aortic rings and mesenteric arteries using organ bath and myograph, respectively. TRPV4 function was studied with fura-2 calcium imaging in endothelial cells cultured from aortas from control and STZ treated rats. TRPV4, caveolin-1 and eNOS expression was investigated in these cells using immunohistochemistry. STZ-treated diabetic rats showed significant endothelial dysfunction characterised by impaired muscarinic-induced vasorelaxation (aortic rings: STZ-diabetics: Emax $=29.6 \pm 9.3 \%$; control: $\max =77.2 \pm 2.5 \% \mathrm{P}<0.001)$, as well as significant impairment in TRPV4-induced vasorelaxation (aortic rings, 4 $\alpha$ PDD STZ-diabetics: Emax= 56.0 $\pm 5.5 \%$; 
control: $\mathrm{Emax}=81.1 \pm 2.1 \% \mathrm{P}<0.001)$. Furthermore, STZ-diabetic primary aortic endothelial cells showed a significant reduction in TRPV4-induced intracellular calcium elevation $(\mathrm{P}<0.05)$ compared with the control group. This was associated with significantly lower expression of TRPV4, caveolin-1 and eNOS and this was reversed by insulin treatment of the endothelial cultures from STZ -diabetic rats. Taken together, these data are consistent with the hypothesis that signalling through TRPV4, caveolin-1, and eNOS is downregulated in STZdiabetic aortic endothelial cells and restored by insulin treatment.

\section{Key words:}

Diabetes; TRPV4; caveolae; eNOS; endothelial dysfunction; insulin

\section{Introduction}

Cardiovascular diseases (CVDs) contribute to approximately $31 \%$ of deaths globally (WHO, 2015). Diabetes mellitus is a pandemic metabolic disease characterised by chronically elevated blood glucose concentration (hyperglycaemia) due to insulin dysfunction which is attributed to insufficient -or blunted- insulin secretion and/or decreased tissue sensitivity to insulin (American Diabetes Association, 2012). Approximately 387 million people are diabetics globally, and diabetes mellitus accounts for approximately 4.9 million deaths annually, which is a death every $6 \mathrm{~s}$ (IDF, 2017). Managing diabetes complications is expected to cost the NHS in the UK approximately $£ 14$ billion by 2035 in comparison to the current expenditure of approximately $£ 8$ billion on managing a variety of complications resulting from endothelial dysfunction (Diabetes UK, 2012; Hex et al., 2012). Endothelial dysfunction is characterised by compromised endothelium-dependent vasorelaxation, and as a consequence diabetics become 
vulnerable to limb infections and end-organ damage such as nephropathy, neuropathy as well as retinopathy (Shamsaldeen et al., 2018).

Endothelium-dependent vasorelaxation is mediated by three main pathways: (1) nitric oxide (NO), (2) prostacyclin and (3) endothelium-derived hyperpolarization factor (EDHF) (Tabit et al., 2010). NO is generated through the oxidation of L-arginine into Lcitrulline by eNOS (Lin et al., 2003) and diffuses through vascular smooth muscle cells where it activates soluble guanylyl cyclase that generates cyclic guanosine-3,5monophosphate (van den Oever et al., 2010), which induces vasorelaxation (Cohen et al., 1999; Dong et al., 1998; Murphy and Brayden, 1995b; Poulos, 2006). The EDHF pathway involves a number of potassium channels (Chen et al., 1988) such as BKCa (K $\mathrm{K}_{\mathrm{Ca}} 1.1$ ) (Huang et al., 2000), SK $\mathrm{Ca}_{\mathrm{Ca}}$ (Murphy and Brayden, 1995a) and IK $\mathrm{K}_{\mathrm{Ca}}\left(\mathrm{K}_{\mathrm{Ca}} 3.1\right.$ ) (Zygmunt and Högestätt, 1996).

However, the contribution of each vasodilatory pathway varies in different vascular beds. EDHF is considered as the main vasodilatory pathway in small resistance arteries such as mesenteric arteries (Sandow and Hill, 2000; Shimokawa et al., 1996; Widmann et al., 1998). Such an effect of EDHF might be attributed to expanded myoendothelial gap junctions in smaller arteries that furnish sites for electrical communication between the endothelium and vascular smooth muscle (Sandow and Hill, 2000). In contrast, the NO pathway is identified as the primary mediator in large arteries (Widmann et al., 1998) such as aorta.

Members of the transient receptor potential (TRP) ion channel family make important contributions to vascular tone as components of the NO and EDHF pathways. Western blotting, RT-PCR and immunohistochemistry studies have identified 21 distinct 
TRP ion channels in vascular smooth muscle cells (VSMCs), all TRPCs (TRPC1-7) and TRPMs (TRPM1-8) in addition to TRPV1-TRPV4 as well as TRPP1 and TRPP2, while similar channels were also found in endothelium with the exception of TRPM5 and TRPV3 (Kwan et al., 2007; Watanabe et al., 2008). These TRP cation channels may influence vascular tone regulation in both systemic and pulmonary circulations (Watanabe et al., 2008). Pharmacological studies showed the expression of TRPV4 as a functional component of endothelial cells in dilating mouse mesenteric arteries, carotid artery, rat aortic rings and carotid artery, in addition to mesenteric and cerebral arterial VSMCs as well as in aortic myocytes (Baylie and Brayden, 2011; Saliez et al., 2008). Endothelial cell TRPV4, activated by shear stress or GPCR activation contributes to vascular tone in an endothelium-dependent manner by providing a $\left(\mathrm{Ca}^{2+}\right)$ influx route and thereby generating EDHF (Bagher et al., 2012; Dora et al., 2000; Inoue et al., 2009).

In addition TRPV4 plays a role in cholinergic-mediated endothelium-dependent vasorelaxation through a novel mechanism that involves $\mathrm{Ca}^{2+}$ influx through an endothelium derived factor, 11,12 -Epoxyeicosatrienoic acid (11,12 EET) activating TRPV4 on VSMCs (Earley et al., 2005). TRPV4-mediated $\mathrm{Ca}^{2+}$ entry activates and opens large-conductance calcium-activated potassium channels ( $\left.\mathrm{K}_{\mathrm{ca}} 1.1\right)$ inducing membrane hyperpolarization in VSMCs and thereby vasorelaxation (Earley et al., 2005; Freichel et al., 2005). Moreover, 11,12 EET was shown to facilitate TRPV4 complex formation with ryanodine receptors and $\mathrm{K}_{\mathrm{Ca}_{\mathrm{a}}} 1.1$ in VSMCs and hence facilitate vasorelaxation (Mustafa et al., 2009).

Increasing evidence points to dysfunction in TRPV4 as a contributor to vascular dysfunction in diabetes. A study conducted by Ma et al. (2013) demonstrated TRPV4 
downregulation in mesenteric artery endothelium from streptozotocin (STZ) treated rats together with reduced small conductance calcium-activated potassium channel $\left(\mathrm{K}_{\mathrm{Ca}} 2.3\right)$ function. Another study concluded that TRPV4 expression and function is downregulated in retinal microvascular endothelial cells from STZ-treated rats or after incubation of control cells in high glucose medium (Monaghan et al., 2015).

This study aimed to further investigate vascular dysfunction in an STZ-treated rat model of type 1, insulin dependent, diabetes. We first examined cholinergic and TRPV4 induced vasorelaxation in intact aortic rings from control and STZ-treated rats. Using primary cultures of aortic endothelial cells from these tissues, we compared expression levels and function of TRPV4 and correlated this with changes in eNOS expression and caveolin 1 and attempted to reverse changes with insulin treatment. Some of these findings have been presented as an oral communication at the British Pharmacological Society (Shamsaldeen et al., 2015).

\section{Materials and methods}

\subsection{Diabetes induction}

Male Wistar rats (350-450g) (Charles River Ltd, UK) were kept in the Biological Services Unit in social pairs under standard housing conditions with freely available food and water at controlled temperature $20 \pm 2^{\circ}$, humidity at $55 \pm 10 \%$, and $12 \mathrm{~h}$ day-night cycle. All studies were approved by the University of Hertfordshire Institutional Animal Welfare and Ethics review committee and conducted in accordance with guidelines established by the Animals (Scientific Procedures) Act, 1986 and European directive 2010/63/EU under PPL70/7732. Rats were randomised for STZ or control injection based 
upon baseline body weight. For STZ diabetes induction, rats were administered a single injection of $65 \mathrm{mg} / \mathrm{kg}$ streptozotocin (STZ; dissolved in $20 \mathrm{mM}$ citrate buffer $\mathrm{pH} 4.5$ ) intraperitoneally (i.p., DV 10ml/kg) (de la Garza-Rodea et al., 2010). For $48 \mathrm{~h}$ following STZ or control ( $20 \mathrm{mM}$ citrate buffer, $\mathrm{pH} 4.5$ ) injection an additional choice of $2 \%$ sucrose solution was provided, to avoid the initial hypoglycaemia that is seen following STZ injection. After injection, food was changed from 14\% protein (LabDiet 5LF2, EURodent Diet $14 \%$ ) to a protein rich diet 22\% protein (LabDiet 5LF5, EURodent Diet 14\%), to compensate diabetes-induced protein loss. Body weight was monitored every day for a minimum of 2 weeks post injection, and hyperglycaemia was confirmed by testing a drop of tail vein blood (Accu-check blood glucose monitor). Rats showing an elevated blood glucose $>16 \mathrm{mmol} / \mathrm{I}$ were considered diabetic. Blood glucose levels were measured at three time periods; (i) Prior to STZ or vehicle injection, (ii) 2-7 days post injection, and (iii) Prior to euthanizing between 8 to 14 days post injection. All rats were euthanised by a schedule 1 procedure of $\mathrm{CO}_{2}$ asphyxiation and spinal dislocation.

Vascular studies were blinded. However, as the experimental design objectives required treatments to be applied to cells to reverse diabetic effects, blinding was not applied to cell studies.

\subsection{Vascular studies}

Isometric tension studies were conducted as previously described (Dhar et al., 2010). Rat thoracic aorta from control-treated (vehicle) and STZ-treated diabetic rats were freshly isolated and cleaned from connective tissue (de-adventitia) using autoclaved forceps and scissors. The aorta was then cut into aortic rings $(3-4 \mathrm{~mm})$ and mounted under $1 \mathrm{~g}$ resting tension in $15 \mathrm{ml}$ Bennett isolated tissue organ baths containing Krebs 
solution bubbled with $95 \% \mathrm{O}_{2}$ and $5 \% \mathrm{CO}_{2}$ maintained at $37^{\circ} \mathrm{C}$. Resting tension of $1 \mathrm{~g}$ was used as studies have shown that induced release of EDRF is more effective against vasopressor tone at low degrees of passive stretch (Dainty et al., 1990). Aortic rings were equilibrated for $90 \mathrm{~min}$ prior to pre-contraction with noradrenaline (300nM), followed by vasorelaxation via cumulative treatment with carbachol (30nM-300 $\mu \mathrm{M})$ and

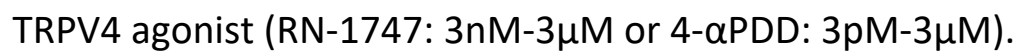

Mesenteric arteries were examined in a four-channel myograph (DMT). Segments of superior mesenteric arteries were threaded with stainless steel wire $40-\mu \mathrm{m}$ thick and carefully stretched laterally in myograph wells, while the tension force was monitored with LabChart 7 software. Tissues were equilibrated for approximately $30 \mathrm{~min}$ prior to pre-contraction with noradrenaline $(\mathrm{NA} ; 10 \mu \mathrm{M})$, followed by vasorelaxation via cumulative treatment with carbachol $(30 \mathrm{M}-300 \mu \mathrm{M})$ and TRPV4 agonist (RN-1747: 3nM$30 \mu \mathrm{M})$.

To measure the extent of vasorelaxation, the $\mathrm{NA} \mathrm{EC}_{80}$-induced contraction was normalised as $0 \%$ vasorelaxation. Each relaxation response was normalised as a percentage of the $\mathrm{NA} \mathrm{EC} \mathrm{C}_{80}$-induced contraction, after which values were subtracted from 0 . The maximum vasorelaxation that reached $0 \mathrm{~g}$ tension force was $100 \%$.

\subsection{Primary aortic endothelial cells isolation}

Primary endothelial cell cultures were used to examine the expression level of TRPV4, eNOS and caveolin-1 with laser scanning confocal microscopy. In addition, primary endothelial cells were studied with calcium imaging fluorescence microscopy. 
Rat aorta was freshly isolated and plunged into sterile Hank's balanced salt solution (HBSS) (Battle et al., 1994). Primary cells were isolated aseptically in a laminar air flow cabinet. Briefly, the aorta was cleaned from the connective tissue using autoclaved forceps and scissors. The aorta was then cut into small rings $(2-3 \mathrm{~mm})$ which were transferred into a sterile tube containing warm medium $199(10 \mathrm{ml})$ containing collagenase and agitated for $90 \mathrm{~min}$ at $37^{\circ}$ (Battle et al., 1994; Ding et al., 2000). The collagenase activity was then stopped with 1-2ml new born calf serum (Ding et al., 2000). A wide mouth pipette was forcibly used to flush the aortic rings to dislodge any possible loosely adherent endothelial cells (Ding et al., 2000). The aortic rings were aseptically removed using a sterile pipette leaving a sterile falcon tube containing a mixture of medium 199 containing collagenase, bovine calf serum and dispersed endothelial cells, which was then centrifuged for 5-min at $200 \mathrm{~g}$ at $25^{\circ}$ (Battle et al., 1994). The supernatant was discarded and small pellets were then re-suspended in collagenase free media 199 (3ml) (Ding et al., 2000). The re-suspended pellet was then plated on collagen coated $t-25$ flasks and the flask was left in the incubator $\left(5 \% \mathrm{CO}_{2}\right.$, $37^{\circ} \mathrm{C}$ ) for $25-30 \mathrm{~min}$ (Dolman et al., 2004). The media was then aspirated and the recently adhered cells were washed twice with HBSS to remove any impurities, debris or ASMCs (Battle et al., 1994). Then 3ml complete DMEM containing horse serum (15\%) and foetal calf serum (4\%), endothelial cell growth factor $75 \mathrm{micg} / \mathrm{ml}$, and heparin powder $(0.005 \% \mathrm{w} / \mathrm{v})$ in addition to streptomycin-penicillin $1 \mathrm{x}$ was added (Battle et al., 1994; Ding et al., 2000). After 3 days, half of the media was changed and left for another 3 days. Within 5 days, clusters of endothelial cells were detected (Shamsaldeen et al., 2018). 


\subsection{Calcium imaging with Fura-2 cells}

Primary endothelial cells were dissociated with trypsin and seeded on autoclaved glass coverslips (0.16-0.19mm thick) coated with poly-L-lysine, placed in wells of 6 well culture plates. Complete endothelial media $(2 \mathrm{ml})$ was added to flood each well and culture plates left in the incubator overnight. Cells were washed and media (containing treatments or without treatments) was changed until endothelial cells became $70 \%$ confluent. The cells were then washed 3-5 times with Hank's buffer (HB) (containing $\mathrm{KCl}$ 5.6mM, NaCl 138mM, NaHCO3 4.2mM, NaH2PO4 1.2mM, CaCl2 2.6mM, MgCl2 1.2mM, glucose $10 \mathrm{mM}$ and HEPES $10 \mathrm{mM} \mathrm{pH} 7.4$ ) (Smith et al., 1999). Fura-2AM incubation solution was composed of HB with Fura-2AM ( $5 \mu \mathrm{M})$, pluronic F-127 (2\%), FBS (2\%) (Huang et al., 1993; Ma et al., 2011). Cells were incubated with Fura-2AM solution in the dark at room temperature for 45-60 min (Ma et al., 2011). Afterward, coverslips were washed with $\mathrm{HB}$ for 5-7 times to remove the extracellular Fura-2AM, and the coverslip was incubated with $\mathrm{HB}$ of FBS (2\%) in the dark at room temperature for 30 min to allow more complete hydrolysis of intracellular Fura-2AM. Thereafter, coverslips were washed for 5 times with HB before starting treatment (Huang et al., 1993). The coverslip was then placed under the Nikon Eclipse TE200 epifluorescence microscope imaged with a x40 immersion objective. Baseline readings were recorded for a minute before adding 4aPDD (1mM) in HBS buffer. Frame fluorescence readings every five $s$ for a further 9 min were recorded for intracellular Ca2+ measurement through fura-2 340/380 ratioing. Image analysis was performed using Scientific Image Processing IPLab software version 4.04 . 


\subsection{Confocal laser scanning microscopy}

Primary endothelial cells were seeded on autoclaved poly-L-lysine coated glass coverslips (0.16-0.19mm thick). Cells were grown to reach approximately $70 \%$ confluency. Endothelial cells were labelled with acetylated LDL. Briefly, coverslips were washed 5 times with HBSS. Cells were then washed with serum free DMEM. Thereafter, the cells were incubated with acetylated LDL $(10 \mu \mathrm{g} / \mathrm{ml}$ in serum free media) in the incubator for $4 \mathrm{~h}$. The coverslips were then washed with HBSS for 5 times before being incubated with paraformaldehyde (4\%) in the dark at room temperature for 1 hour to fix the cells. Afterward, the cells were permeabilised by incubation with Triton-X100 (0.5\% in HBSS) for $10 \mathrm{~min}$ in the dark at room temperature. The coverslips were washed 3 times with HBSS. Next, cells were incubated with rabbit primary antibody (1:200) for TRPV4, eNOS or caveolin-1 in IFF blocking solution composed of phosphate buffered saline $\mathrm{pH} 7.4$, bovine serum albumin BSA (1\%) and foetal calf serum FCS (2\%) overnight at $4^{\circ} \mathrm{C}$. Thereafter, cells were washed 5 times with HBSS before being incubated with the goat secondary anti rabbit antibody $(1: 1000)$ for $2 \mathrm{~h}$ at room temperature. Coverslips were then washed 5 times with HBSS and mounted on microscope glass slides with a drop of mounting media containing DAPI which stains the nucleus. Cells were visualised with Nikon C1 confocal laser scanning microscope and EZ-C1 silver version 3.9 software. The images were then uploaded to Image $1.46 \mathrm{r}$ software for quantitative analysis. The expression of TRPV4, caveolin-1 and eNOS was quantified by ImageJ through selecting cells as regions of interest and then measuring the fluorescence intensity per cell $(n=3-4$ cells/coverslip) with calculating the average of the cells in a coverslip. The average intensity was then normalized to the fluorescence intensity of the untreated control cells for each antibody (Shamsaldeen et al., 2018). 


\subsection{Data and statistical analysis}

Data were analysed through GraphPad Prism (version 5). The number of different experiments conducted from different animals (tissues, cells) is referred as the studies group size (n). Data are expressed as mean \pm S.E.M and compared through one-way ANOVA with post hoc Tukey's test, repeated measures two-way ANOVA with post hoc Bonferroni's test or unpaired student t-test. The P-value was considered significant when less than 0.05

\subsection{Reagents}

Bicinchoninic acid assay (BCA) reagents, protein assay reagent $A(11881345)$ and protein assay reagent B (10475944), and cell culturing reagents, Dulbecco's Modified Eagle Medium (DMEM) (10135082), newborn bovine calf serum (10014173), antibiotic/antimycotic solution (100x) (10101043), trypsin 2.5\% (10217723), Hanks' Balanced Salt Solution (HBSS) (10X) (10227632), Membrane filter Immobilon-P transfer membranes $0.45 \mu \mathrm{m}$ pore size (IPVH00010) were all purchased from Fisher-Scientific (Loughborough, UK). Streptozotocin (S0130), carbamoylcholine chloride (carbachol) (C4328), L-noradrenaline (A7257), 4a-Phorbol 12,13-didecanoate (4- $\alpha$ PDD) (C0130), insulin from bovine pancreas (16634), endothelial cell growth supplement from bovine pituitary (E0760), heparin sodium salt from porcine intestinal mucosa (10KU) (H3149), collagen from rat tail Bornstein and Traub Type I (C7661), luminol (A8511), p-coumaric acid (C9008), goat anti-rabbit IgG (whole molecule)-peroxidase antibody (a6154) produced in goat and mouse monoclonal anti- $\beta$-actin-peroxidase antibody (A3854) were all purchased from Sigma Aldrich (Gillingham, UK). Interferon- $\gamma$, rat, recombinant, E. coli (407321) was purchased from Merck chemicals (Nottingham, UK). Biotinylated protein 
ladder detection pack (7727S) was purchased from New England biolabs (Hitchin, UK). Rabbit anti-TRPV4 polyclonal antibody (ab63003) was purchased from Abcam (Cambridge, UK). Rabbit anti caveolin-1 polyclonal antibody (PA5-17447) and rabbit eNOS polyclonal antibody (PA3-031A) were purchased from Thermo Fisher Scientific (Northumberland, UK). Goat anti-rabbit IgG fluorescein antibody (FI-1000) and mounting medium with DAPI (H-1500) were purchased from Vector laboratories (Peterborough,

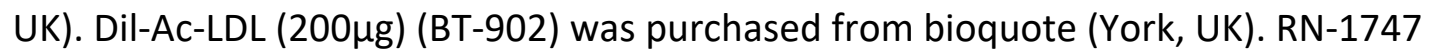
(3745) was purchased from Tocris (Bristol, UK). Fura-2, AM, cell permeant (F-1221) and Pluronic ${ }^{\circledR}$ F-127 (P-6866) were purchased from Life Technologies Ltd (Paisley, UK).

\section{Results}

\subsection{STZ-treated rats showed significant increase in blood glucose}

Ninety-six percent of STZ-injected rats developed hyperglycaemia characterised by blood glucose concentration $>16 \mathrm{mmol} / \mathrm{l}$ and were included in the study analyses as the STZ-diabetic rat group. Blood glucose was significantly elevated in STZ-diabetic rats (>4fold) between 8 to 14 days post injection compared with age-matched control rats (STZdiabetic: $31.6 \pm 1.2 \mathrm{mmol} / \mathrm{l}$; control: $6.58 \pm 0.13 \mathrm{mmol} / \mathrm{I} P<0.001$, Fig. 1 ). 


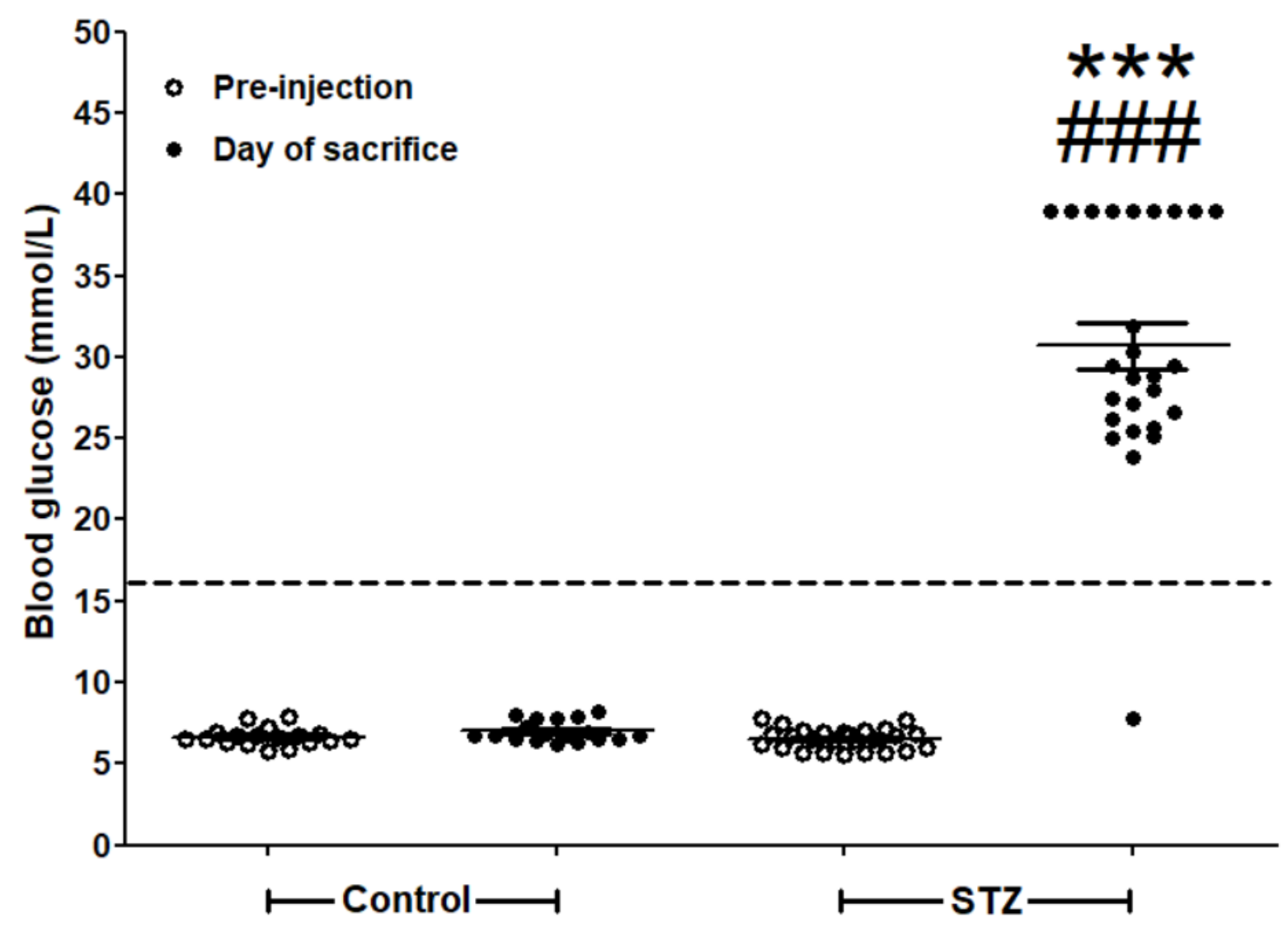

Fig. 1 Effect of streptozotocin (STZ) injection on blood glucose concentration measured pre-injection and between 8 to 14 days post-injection (day of sacrifice). Data presented as mean \pm S.E.M, control $(N=18)$ and $(S T Z=$

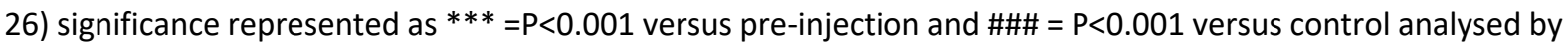
Bonferroni two-way ANOVA. Dotted line shows diabetes threshold glucose concentration (16 mmol/I). One STZinjected rat that did not develop hyperglycaemia and diabetes was excluded from data analyses.

\subsection{Aortic rings from STZ-treated rats showed significant reduction in endothelial cholinergic and TRPV4-induced vasorelaxation}

Aortic rings from STZ -diabetic rats were constricted with noradrenaline (300nM) before being relaxed with carbachol $(30 \mathrm{nM}-300 \mu \mathrm{M})$. Carbachol $\mathrm{E}_{\max }$ was significantly reduced in rings from STZ -diabetic rats compared to aortic rings from control rats, with no effect on $\mathrm{EC}_{50}$ (STZ-diabetics: $\mathrm{EC}_{50}=0.8 \mu \mathrm{M} \& \mathrm{E}_{\max }=29.6 \pm 9.3 \%$; control: $\mathrm{EC}_{50}=0.7 \mu \mathrm{M} \&$ $E_{\max }=77.2 \pm 2.5 \% \mathrm{P}<0.001$, Fig. $\left.2 \mathrm{~A}\right)$. As relaxation to carbachol was compromised in aortic 
rings isolated from STZ-diabetic rats (Fig. 2A), noradrenaline-constricted aortic rings were treated with TRPV4 agonists (4aPDD and RN-1747). Aortic rings from STZ -diabetic rats showed significant reduction in 4aPDD-induced vasorelaxation compared to aortic rings from control rats (STZ-diabetics: $\mathrm{EC}_{50}=0.5 \mu \mathrm{M} \& \mathrm{E}_{\max }=56.0 \pm 5.5 \%$; control: $\mathrm{EC}_{50}=$ $0.1 \mu \mathrm{M} \& \mathrm{E}_{\max }=81.1 \pm 2.1 \% \mathrm{P}<0.05$, Fig. $\left.2 \mathrm{~B}\right)$. Another TRPV4 agonist (RN-1747) was examined to confirm the observation obtained with 4 QPDD. Aortic rings from STZ diabetic rats also showed significant reduction in RN-1747-induced vasorelaxation compared to aortic rings from control rats (STZ-diabetics: $\mathrm{EC}_{50}=1 \mu \mathrm{M} \& \mathrm{E}_{\max }=21.4 \pm 7.7 \%$; control: $\mathrm{EC}_{50}=61 \mathrm{nM} \& \mathrm{E}_{\max }=56.2 \pm 8.6 \% \mathrm{P}<0.05$, Fig. 2C).

We next looked at responses in superior mesenteric arteries as an example of resistance vessels. Mesenteric arteries' response to carbachol and RN-1747 was recorded to compare mesenteric arteries from STZ-injected rats with mesenteric arteries from control rats. The diameter of mesenteric arteries was not significantly different (STZ-diabetics: $290.6 \pm 16.2 \mu \mathrm{m}$; control: $318.8 \pm 11.7 \mu \mathrm{m}$ P>0.05). As shown in Fig. 2D, carbachol-induced vasorelaxation was significantly reduced in arteries from STZ-diabetic rats compared to arteries from control rats (STZ-diabetics: $\mathrm{EC}_{50}=18 \mu \mathrm{M} \& \mathrm{E}_{\max }=$ 60.3 $\pm 10.1 \%$; control: $\left.\mathrm{EC}_{50}=70.3 \mathrm{nM} \& \mathrm{E}_{\max }=94.0 \pm 4.7 \% \mathrm{P}<0.05\right)$. In parallel to impaired cholinergic-induced vasorelaxation, $\mathrm{RN}$-1747-induced vasorelaxation was significantly reduced in arteries from STZ-diabetic rats compared to arteries from control rats (STZdiabetics: $\mathrm{EC}_{50}=0.3 \mu \mathrm{M} \& \mathrm{E}_{\max }=41.5 \pm 5.7 \%$; control: $\mathrm{EC}_{50}=2.3 \mu \mathrm{M} \& \mathrm{E}_{\max }=79.1 \pm 6.1 \%$ $P<0.05$, Fig. 2E). 


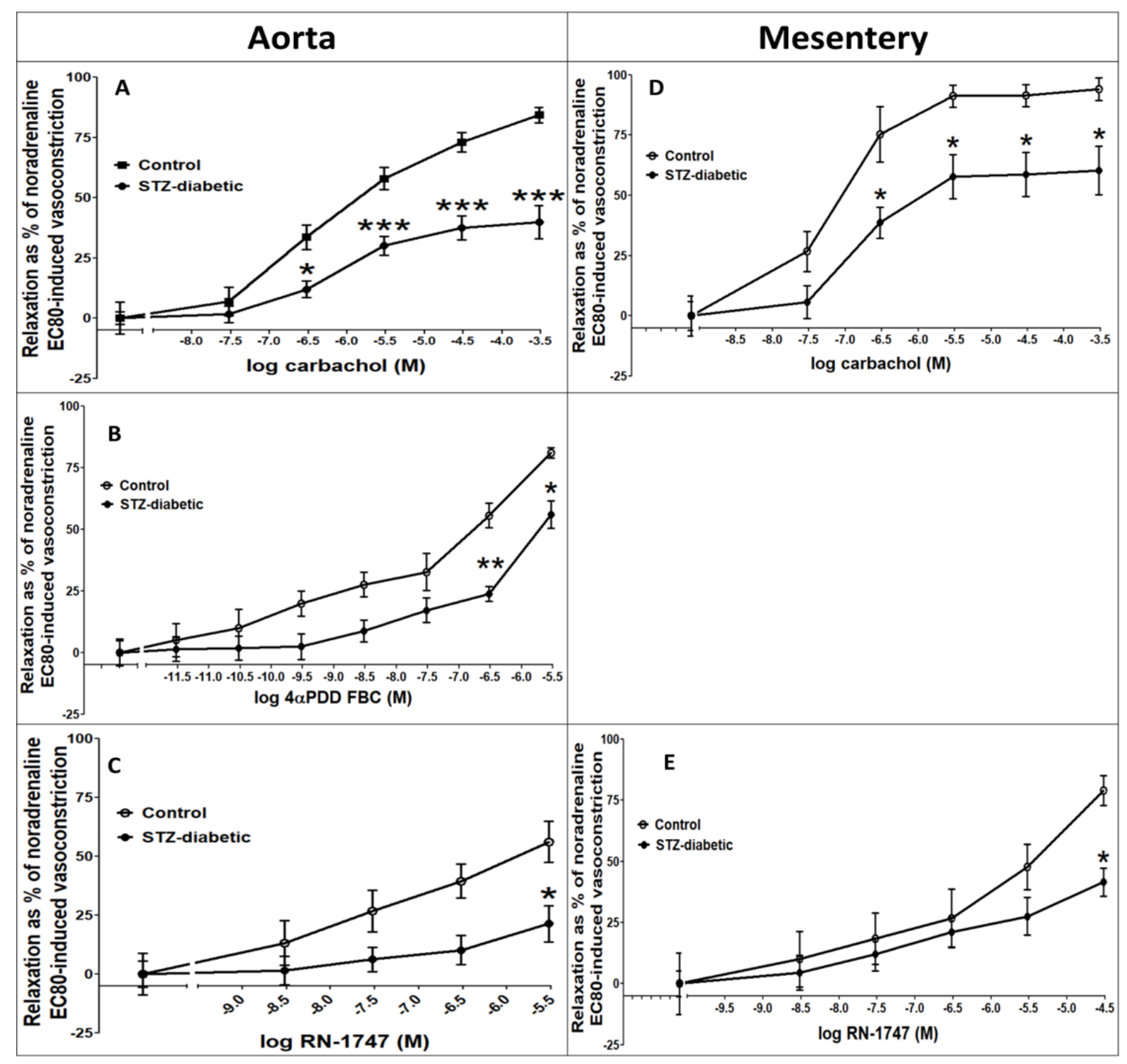

Fig. 2 Carbachol and TRPV4 agonist-induced vasorelaxation normalised to noradrenaline EC80 (300 nM)induced vasoconstriction. (A) Concentration response curves to carbachol of streptozotocin (STZ)-diabetic freshly isolated rat aortic rings compared to control freshly isolated rat aortic rings (STZ-diabetic $n=12$, control $n=10)$. (B) 4- $\alpha$ PDD concentration response curves of STZ-diabetic freshly isolated rat aortic rings compared to vehicle control freshly isolated rat aortic rings (STZ-diabetic $n=4$, control $n=4)$. (C) RN-1747 concentration response curves of STZ-diabetic freshly isolated rat aortic rings compared to vehicle control freshly isolated rat aortic rings (STZ-diabetics $n=6$, control $n=5$ ). (D) Carbachol concentration response curves of STZ-diabetic freshly isolated rat secondary mesenteric arteries compared to control freshly isolated secondary mesenteric arteries (STZ-diabetic $n=4$, control $n=4)$. (E) RN-1747 concentration response curves of STZ-diabetic freshly isolated rat secondary mesenteric arteries compared to control freshly isolated secondary mesenteric arteries 
(STZ-diabetic $n=5$, control $n=5$ ). Significance is represented as $* P<0.05, * * P<0.01$ and $* * *=p<0.001$ versus control rats analysed by repeated measures two-way ANOVA followed by multiple comparison Bonferroni post-hoc test.

3.3. TRPV4 mediated calcium signalling was significantly reduced in primary aortic endothelial cells from STZ treated rats and reversed with insulin treatment

As reported by others, carbachol and TRPV4 mediated relaxation in aortic rings was shown to be endothelium dependent (Dhar et al., 2010; Earley et al., 2005; Earley et al., 2009), so we next investigated TRPV4 channel function in endothelial cells. As aorta and resistance vessels show the same vasorelaxation mechanisms we chose to explore changes in signalling in aortic endothelial cells. Primary aortic endothelial cells were isolated and grown in t-25 collagen coated culture flasks. After 10-14 days, the flasks were approximately $80 \%$ confluent. The cells were plated on poly-l-lysine coated glass coverslips. STZ-diabetics' endothelial cells were treated with insulin $(1$ and $10 \mu \mathrm{g} / \mathrm{ml}$ equivalent to $0.27 \mathrm{IU} / \mathrm{ml}$ and $2.7 \mathrm{IU} / \mathrm{ml}$ ) for 5 days. Fura-2 calcium imaging was conducted to investigate TRPV4 function.

4aPDD-induced $\mathrm{Ca}^{2+}$ signals showed a significant decrease in aortic endothelial cells from STZ-diabetic rats compared to control endothelial cells (Control endothelial cells: 1.0 \pm 0.2 fura-2 ratio; STZ-diabetics' diabetic endothelial cells: $0.5 \pm 0.13$ fura-2 ratio $P<$ 0.05, Fig. 3). Moreover, endothelial cells from STZ diabetic rats, treated in culture with insulin $0.27 \mathrm{IU} / \mathrm{ml} /$ day for 5 days showed a significant increase in fura-2 ratio in response to $4 \alpha \mathrm{PDD}$, compared to untreated endothelial cells from STZ diabetic rats (STZdiabetics' diabetic aortic endothelial cells treated with insulin $0.27 \mathrm{IU} / \mathrm{ml} /$ day for 5 days: 1.1 \pm 0.1 fura-2 ratio; STZ-diabetics' diabetic endothelial cells: $0.5 \pm 0.13$ fura-2 ratio $P<$ 0.05, Fig. 3). 


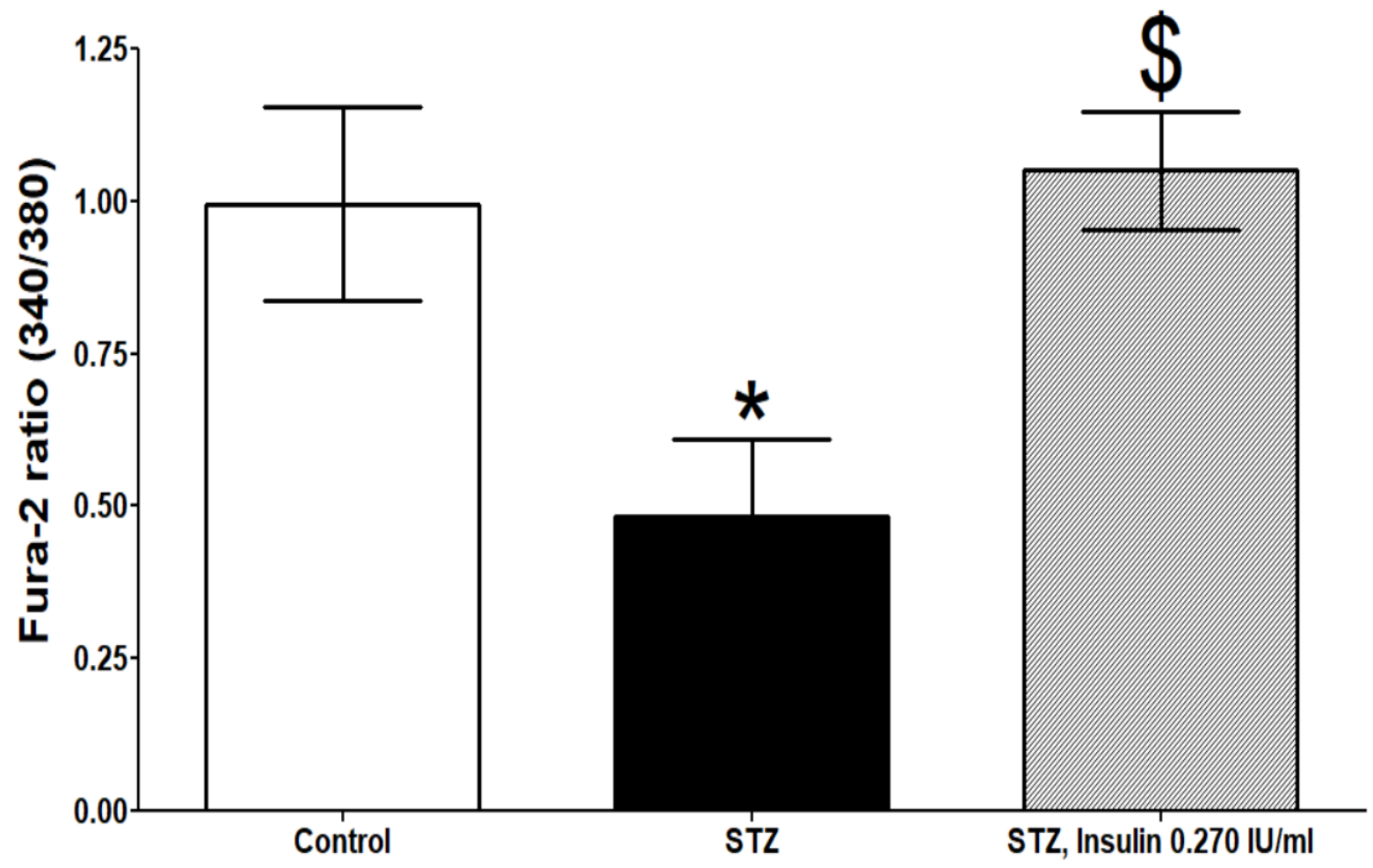

Fig. $34 \alpha$ PDD treatment induced changes in fura-2 ratio in primary rat aortic endothelial cells. Aortic endothelial cells cultured from streptozotocin (STZ)-diabetic rats showed significant reduction in fura-2 ratio due to $4 \alpha$ PDD treatment (STZ-diabetic $n=4$, control $n=4$ ). Aortic endothelial cells cultured from STZ diabetic rats treated with insulin $0.27 \mathrm{IU} / \mathrm{ml}$ showed a significant increase in fura-2 ratio (STZ-diabetic $\mathrm{n}=4$, STZdiabetics' aortic endothelial cells treated with insulin $0.27 \mathrm{IU} / \mathrm{ml} \mathrm{n=4).} \mathrm{Data} \mathrm{shown} \mathrm{as} \mathrm{average} \mathrm{peak} \mathrm{change} \mathrm{in}$ fura-2 ratio $(340 / 380) \pm$ S.E.M. Significance represented as $* P<0.05$ vs control and $\$ P<0.05$ vs STZ-diabetics analysed through one-way ANOVA followed by multiple comparison Tukey post-hoc test.

As well as being reduced in amplitude, the time course of the fura- 2 response to $4 \alpha P D D$ superfusion was slowed, so that the time to fura-2 ratio peak response was significantly delayed (time to fura-2 ratio peak Control: $81.3 \pm 13.5$ s; STZ-diabetic: $202 \pm 23.5$ S, P<0.05, Fig. 4). STZ-diabetic-endothelial cells treated with insulin $0.27 \mathrm{IU} / \mathrm{ml} /$ day for 5 days showed a partial reversal of this slowing that was not significantly different compared to untreated STZ-diabetic endothelial cells (time to fura-2 ratio peak STZ-diabetics' endothelial cells treated with insulin $0.27 \mathrm{IU} / \mathrm{ml} /$ day: $154.5 \pm 40.2 \mathrm{~s}$; STZ-diabetics: $202 \pm 23.5 \mathrm{~s}$ P> 0.05, Fig. 4). 


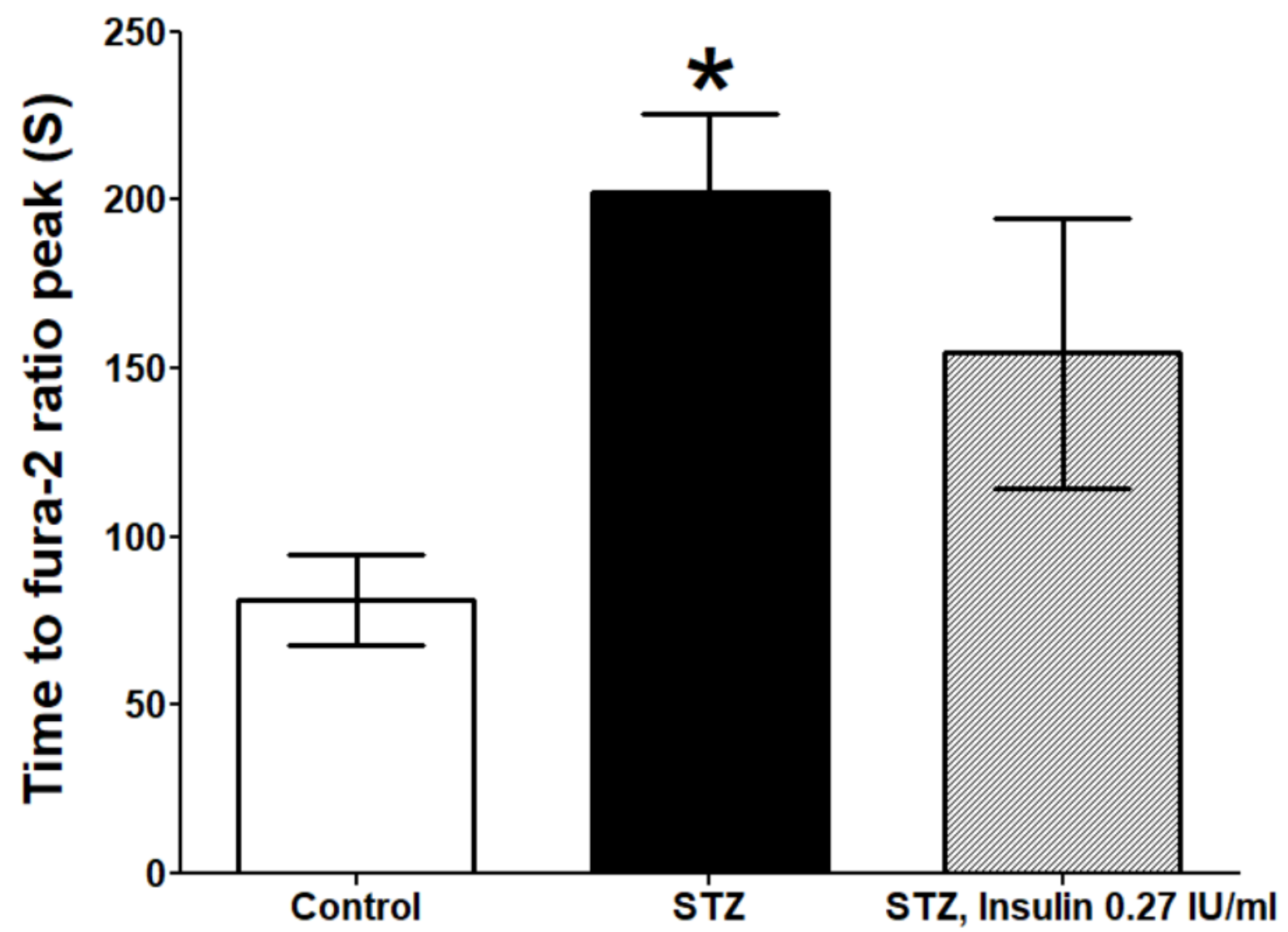

Fig. 4 Peak time for 4aPDD-induced fura-2 ratio change in primary rat aortic endothelial cells. Responses in aortic endothelial cells cultured from streptozotocin (STZ)-diabetic rats showed significant delay in time to fura-2 ratio peak (STZ-diabetic $n=4$, control $n=4$ ). STZ-diabetic aortic endothelial cells treated with insulin 0.27 IU/ml did not significantly alter the delay in time to fura-2 ratio peak (STZ-diabetic endothelial cells $n=4, S T Z$ -

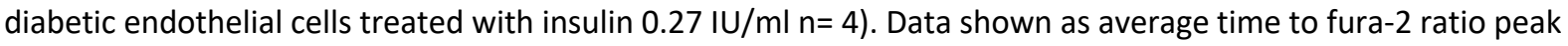
(S) \pm S.E.M. Significance represented as * $\mathrm{P}<0.05$ vs control analysed through one-way ANOVA followed by Tukey post-hoc test. 


\subsection{TRPV4 expression was significantly downregulated in STZ-diabetic rats' primary}

\section{aortic endothelial cells, and reversed by insulin treatment}

The changes in TRPV4 function might be due to reduced TRPV4 expression and or changes in individual channel function. Primary aortic endothelial cells from vehicle control and STZ-diabetic rats were isolated and grown in t-25 collagen coated culture flasks. After 10-14 days, the flasks were approximately $80 \%$ confluent. The cells were plated on poly-l-lysine coated glass coverslips. Endothelial cells from STZ-diabetic rats were treated with insulin ( 1 and $10 \mu \mathrm{g} / \mathrm{ml}$ equivalent to $0.27 \mathrm{IU} / \mathrm{ml}$ and $2.7 \mathrm{IU} / \mathrm{ml}$ ) for 5 days. Afterwards, cells were visualised with a laser scanning confocal microscope (Fig. 5).
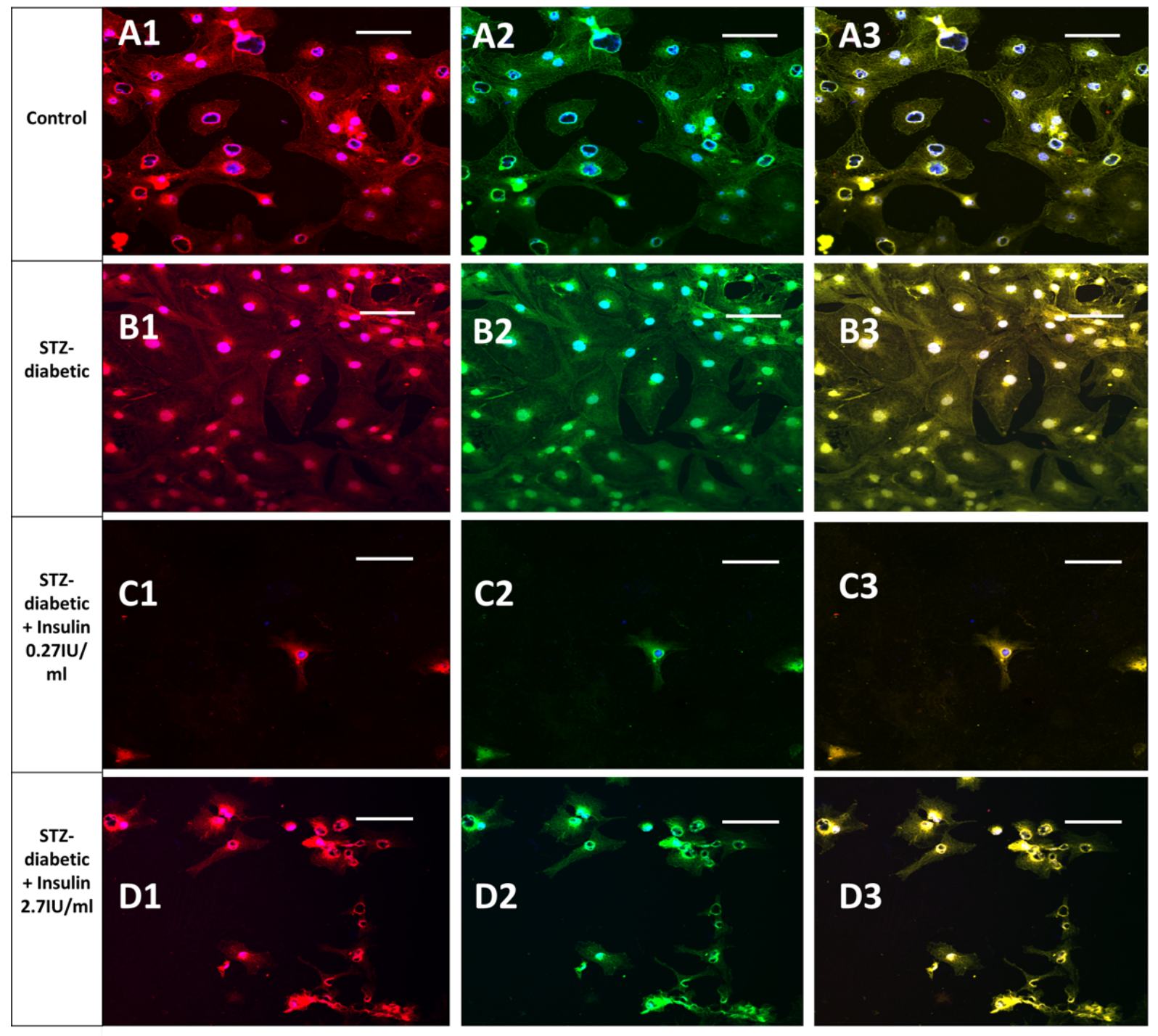
Fig. 5 TRPV4 expression in primary endothelial cells visualised with a laser scanning confocal microscope. Endothelial cells were probed with DAPI to label the nucleus in blue and marked with acetylate oxidised LDL (Ac-ox-LDL) giving the cells the red colour (A1, B1, C1 \& D1). Anti TRPV4 primary antibody probed with secondary fluorescence antibody. TRPV4 was expressed around the nucleus and at the edge of the plasma membrane in vehicle control aortic endothelial cells (A2). STZ-diabetic endothelial cells showed disrupted TRPV4 distribution with less fluorescence (B2). Insulin treatment $0.27 \mathrm{IU} / \mathrm{ml}$ (C2) and $2.7 \mathrm{IU} / \mathrm{ml}$ (D2) per day for 5 days restored TRPV4 distribution in STZ-diabetic endothelial cells to that seen in control cells. Images were overlaid for endothelial marker (red), nucleus marker (blue) and TRPV4 florescence antibody (green) (A3, B3, C3 \& D3). Scale markers are $100 \mu \mathrm{m}$.

The expression profile of TRPV4, caveolin-1 and eNOS was quantified through comparing expression levels of these proteins in endothelial cells cultured from STZdiabetic rats to control rats. In a separate analysis, expression levels in endothelial cells from STZ diabetic rats were compared to endothelial cells from STZ-diabetic rats cultured with insulin 0.27 or $2.7 \mathrm{IU} / \mathrm{ml} /$ day for 5 days. As shown in Fig. 6, endothelial cells cultured from STZ diabetic rats showed significantly lower expression of TRPV4 compared to endothelial cells cultured from control rats (Fig. 6A, $\mathrm{P}<0.01$ ). TRPV4 expression in endothelial cells from STZ diabetic rats was also significantly lower than expression levels after 5 days treatment of cultures with insulin (Fig. 6B, P<0.05). 


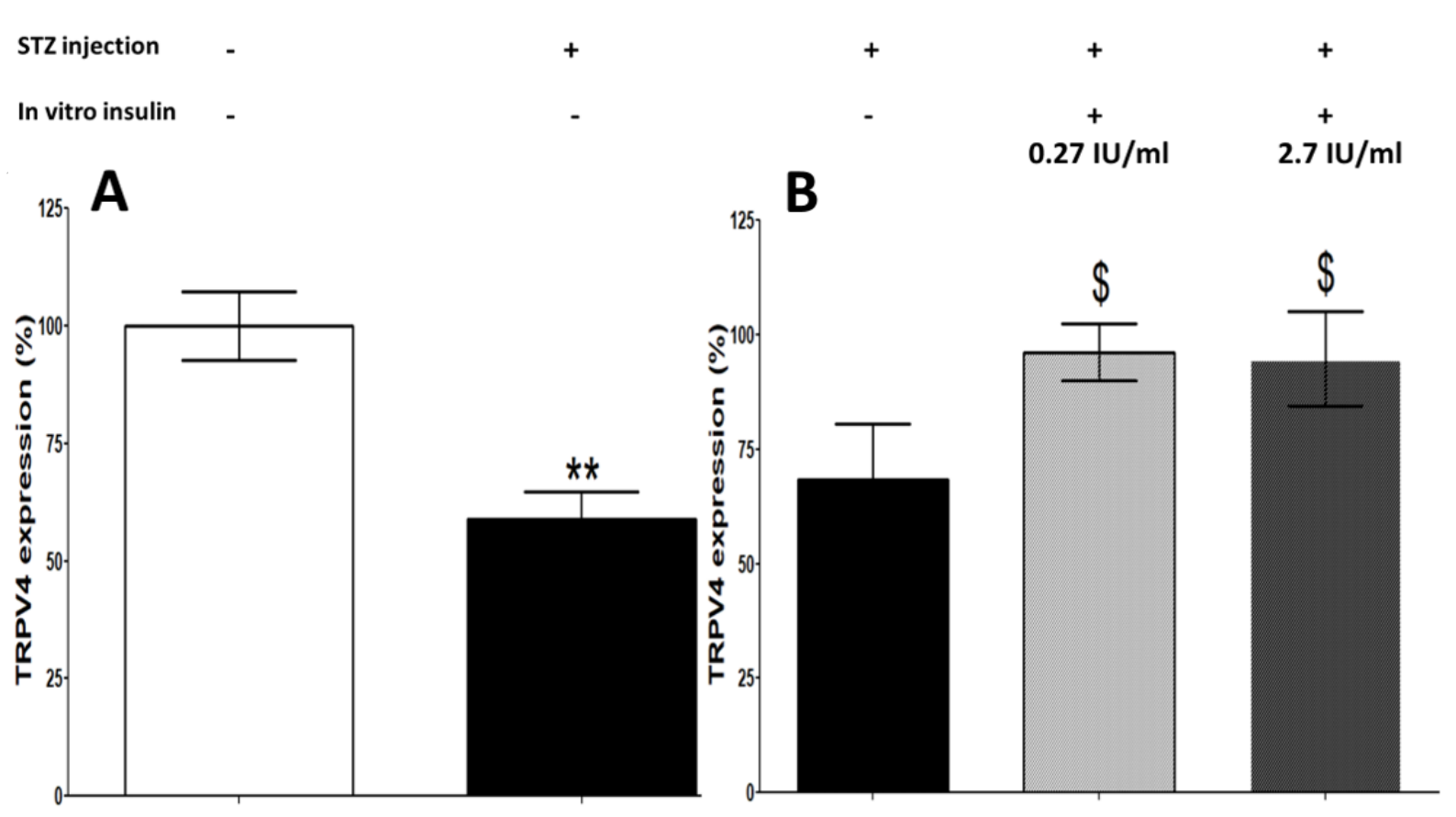

Fig. 6 Total TRPV4 expression in primary rat aortic endothelial cells normalised to control untreated cells. TRPV4 expression was significantly reduced in streptozotocin (STZ)-diabetic' aortic endothelial cells (STZdiabetic $n=8$, control $n=5, P<0.01$ ) analysed through one-way ANOVA with un-paired t-test (6A). STZ-diabetics' aortic endothelial cells treated with insulin $(0.27 \mathrm{IU} / \mathrm{ml}$ and $2.7 \mathrm{IU} / \mathrm{ml})$ showed a significant increase in TRPV4

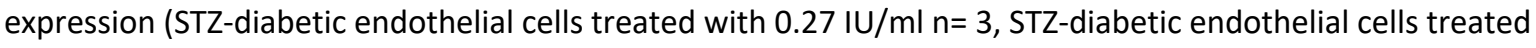
with $2.7 \mathrm{IU} / \mathrm{ml} \mathrm{n}=3$, STZ-diabetic endothelial cells $\mathrm{n}=3, \mathrm{P}<0.05)$ analysed through one-way ANOVA with Tukey post-hoc test (6B). Data shown as average percentage \pm S.E.M. Significance is represented as $* * P<0.01$ vs control, \$ $\mathrm{P}<0.05$ vs STZ-diabetic.

\subsection{Reduced expression of caveolin-1 in STZ-diabetic rats' primary aortic endothelial cells was reversed by insulin treatment}

Caveolae are lipid raft invaginations in the endothelial cell membrane. Caveolin-1 is a major protein component of the endothelial caveolae. Previous studies showed caveolin-1 is associated with TRPV4 (Saliez et al., 2008). Therefore, further studies were conducted on endothelial cells to investigate whether caveolin-1 expression was altered 
in the STZ-diabetic model, and whether in vitro insulin treatment had any effect on caveolin-1 expression. There was intense caveolin immunofluorescence in control endothelial cells and this was much more diffuse and punctate in the cells from STZ diabetic animals (Fig. 7A2 \& B2). Treatment of the cultures from STZ-diabetic animals with insulin $(0.27 \mathrm{IU} / \mathrm{ml}$ and $2.7 \mathrm{IU} / \mathrm{ml})$ restored the expression of caveolin-1, similar to that seen in the control cells (Fig. 7C2,D2).

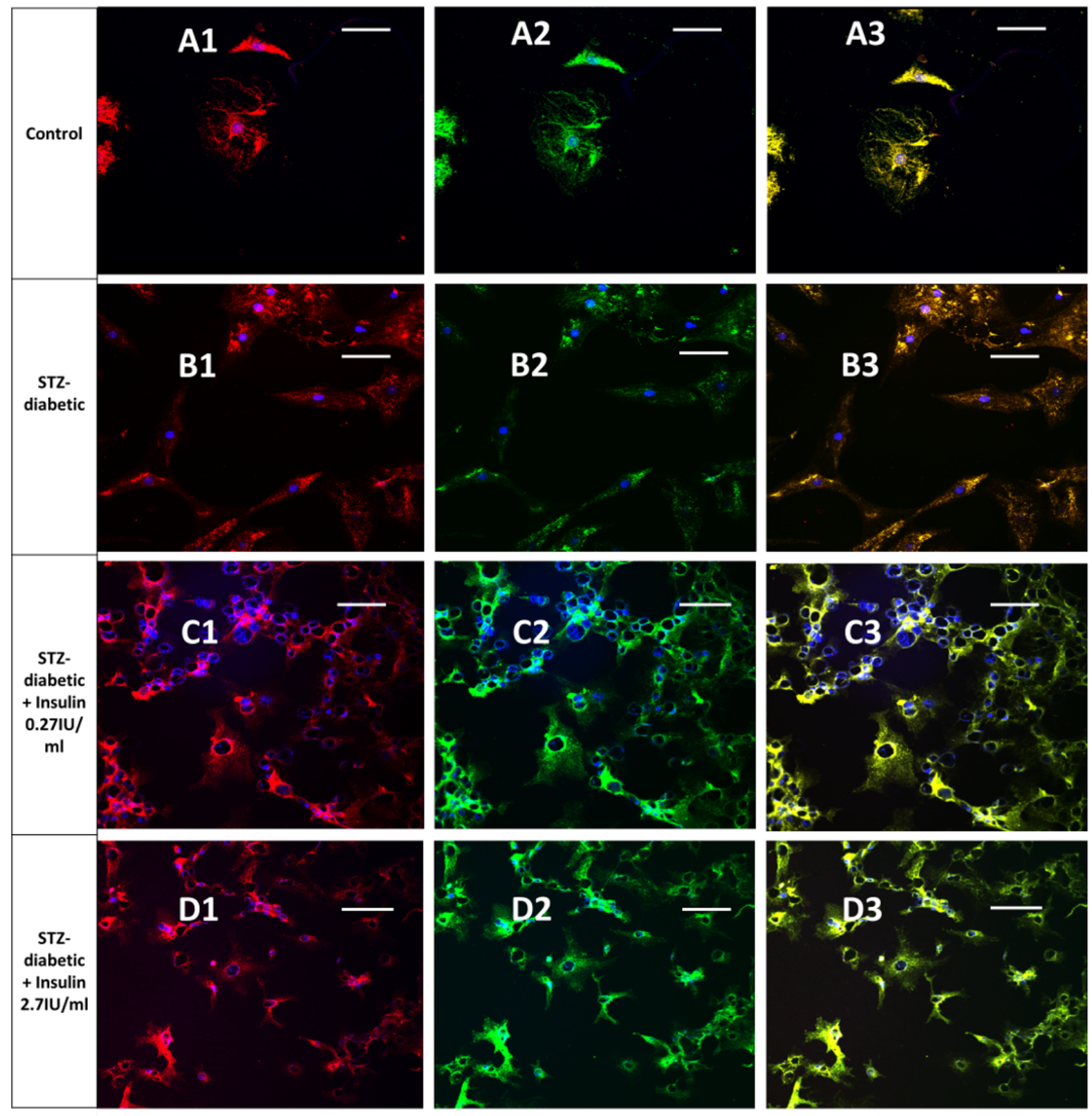

Fig. 7 Caveolin-1 expression in primary endothelial cells visualised with a laser scanning confocal microscope. Endothelial cells were probed with DAPI to label the nucleus in blue and marked with 
acetylate oxidised LDL (Ac-ox-LDL) giving the cells the red colour (A1, B1, C1 \& D1). Anti-caveolin-1 primary antibody probed with secondary fluorescence antibody. Caveolin-1 showed distinct distribution around the nucleus and at the edge of plasma membrane in vehicle control aortic endothelial cells (A2). STZdiabetic endothelial cells showed disrupted caveolin-1 distribution with less caveolin-1 immunofluorescence (B2). Insulin treatment $0.27 \mathrm{IU} / \mathrm{ml}(\mathrm{C} 2)$ and $2.7 \mathrm{IU} / \mathrm{ml}$ (D2) per day for 5 days normalised caveolin-1 distribution in STZ-diabetic endothelial cells. Images were merged to combine endothelial marker (red), nucleus marker (blue) and caveolin-1 florescence antibody (green) (A3, B3, C3 \& D3). Scale markers are $100 \mu \mathrm{m}$.

Total caveolin -1 immunofluorescence was significantly reduced in aortic endothelial cells cultured from STZ- diabetic rats compared to control endothelial cells (Fig. 8A, $\mathrm{P}<0.05)$. Treatment of the aortic endothelial cells cultured from STZ-diabetic rats with insulin $(0.27 \mathrm{IU} / \mathrm{ml}$ and $2.7 \mathrm{IU} / \mathrm{ml})$ for 5 days resulted in a significant increase in caveolin1 immunofluorescence compared to untreated cells from STZ diabetic rats (Fig. 8B, $\mathrm{P}<0.05)$.
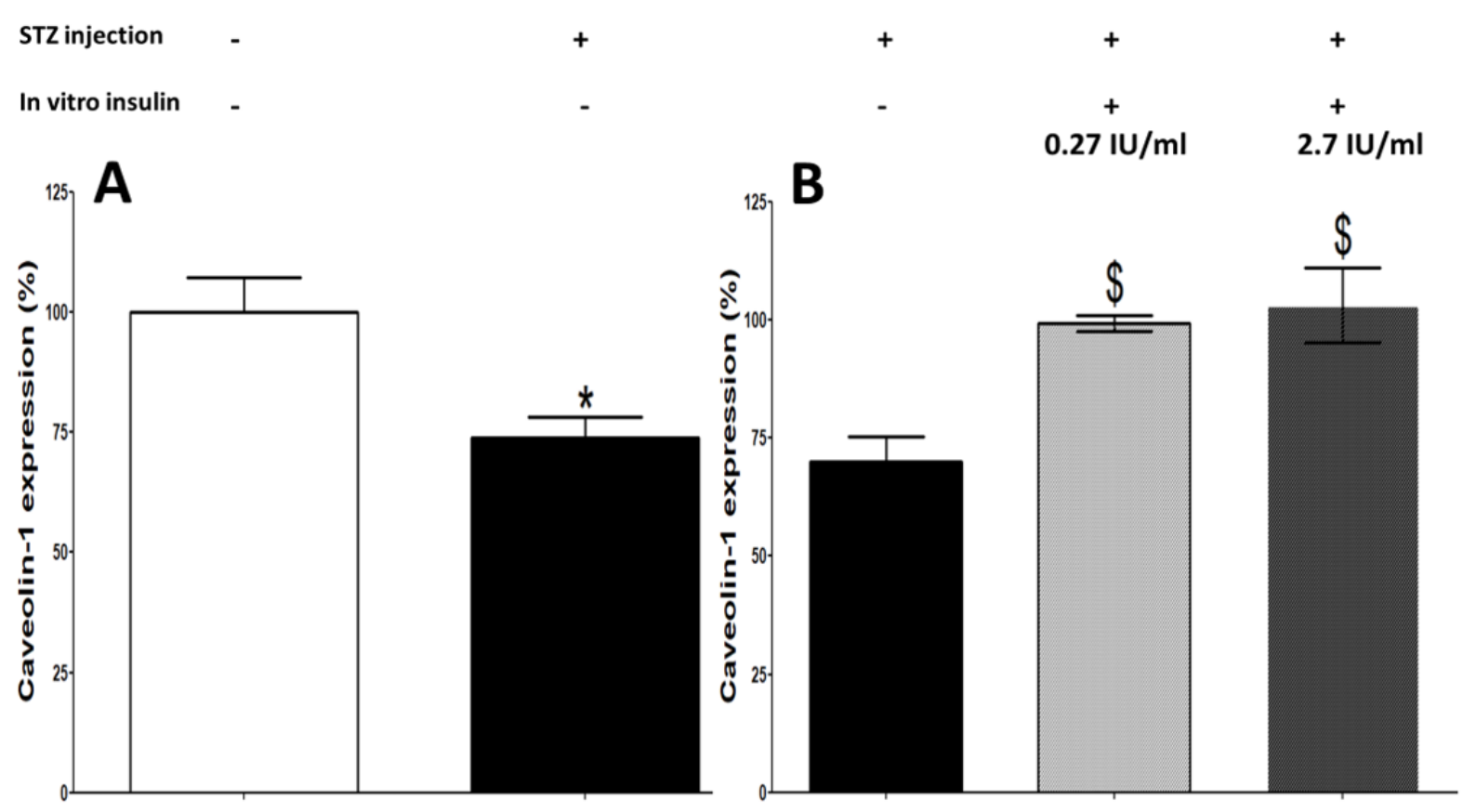

Fig. 8 Total caveolin-1 expression in primary rat aortic endothelial cells cultured from control and streptozotocin (STZ)-diabetic rats and the effect of incubation with insulin. Caveolin-1 expression in aortic 
endothelial cells from STZ-diabetic rats was significantly reduced compared to control (STZ-diabetic $n=4$, control $n=5)(8 A)$. Aortic endothelial cells from STZ-diabetic rats when treated with insulin showed significant increase in caveolin-1 expression (STZ-diabetic endothelial cells treated with $0.27 \mathrm{IU} / \mathrm{ml} \mathrm{n}=3$, STZ-diabetic endothelial cells treated with $2.7 \mathrm{IU} / \mathrm{ml} n=3$, STZ-diabetics endothelial cells $n=3$ ) (8B). Data shown as average percentage \pm S.E.M. Significance is represented as $* \mathrm{P}<0.05$ vs control endothelial cells un-paired t-test, $\$$ $\mathrm{P}<0.05$ vs STZ-diabetic rats, one-way ANOVA with Tukey post-hoc test.

\subsection{Reduced expression of eNOS in STZ-diabetic rats' primary aortic endothelial cells was reversed by insulin treatment}

Endothelial cells constitutively release nitric oxide (NO) that is generated from eNOS through the oxidation of L-arginine to L-citrulline (Cines et al., 1998). eNOS can be stimulated through shear stress (Lüscher and Barton, 1997). Moreover, increased blood shear stress activates membrane bound phospholipase-A2 (PLA-2) which generates arachidonic acid (AA) from membrane cholesterol followed by a series of reactions that yield 11,12 epoxyecosatrienoic acid (EET), a direct TRPV4 activator (Inoue et al., 2009). Previous studies showed that eNOS and caveolin-1 are co-localised in rat kidneys and cultured bovine and rat aortic endothelial cells (Komers et al., 2006; Shamsaldeen et al., 2018; Wang et al., 2009), so it was of interest to investigate the expression of eNOS in these endothelial cell cultures. Therefore, immunocytochemistry studies were conducted which showed significant eNOS immunofluorescence downregulation and disruption in STZ-diabetic aortic endothelial cells compared to cells cultured from control rats and this deficit in STZ-diabetic aortic endothelial cells was significantly reversed by insulin $(0.27 \mathrm{IU} / \mathrm{ml}$ and $2.7 \mathrm{IU} / \mathrm{ml}$ ) treatment of the cultures (Fig. 9\&10, $P<0.001)$. 


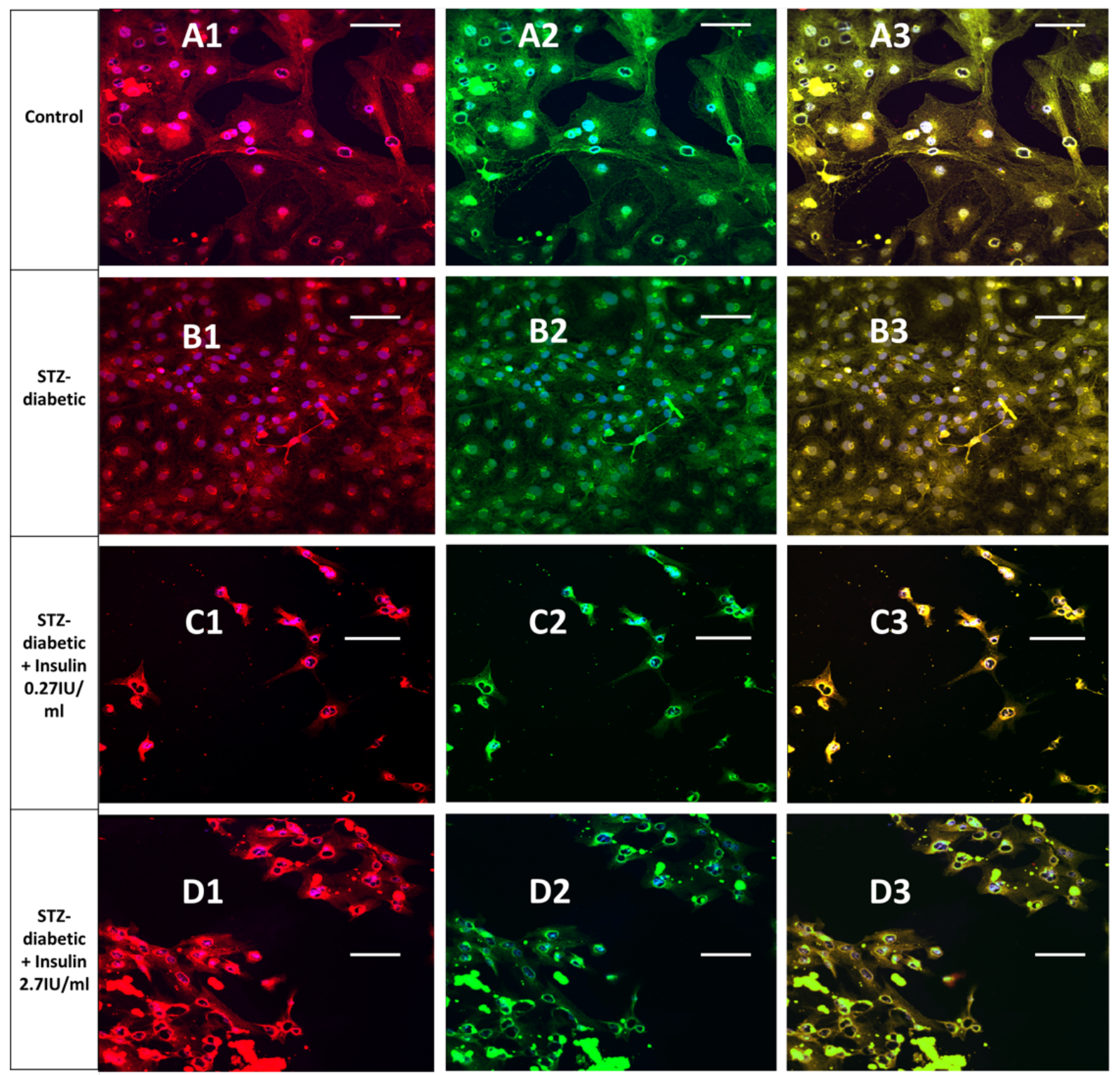

Fig. 9 Endothelial nitric oxide synthase (eNOS) expression in primary endothelial cells visualised with a laser scanning confocal microscope. Endothelial cells were probed with DAPI to label the nucleus in blue and marked with acetylate oxidised LDL (Ac-ox-LDL) giving the cells the red colour (A1, B1, C1 \& D1). Anti eNOS primary antibody probed with secondary fluorescence antibody. eNOS showed distinct distribution around the nucleus and at the edge of plasma membrane in vehicle control aortic endothelial cells (A2). Endothelial cells cultured from STZ -diabetic rats showed diffuse eNOS (B2). Insulin treatment $0.27 \mathrm{IU} / \mathrm{ml}$ (C2) and $2.7 \mathrm{IU} / \mathrm{ml}$ (D2) per day for 5 days restored eNOS distribution in endothelial cells cultured from STZ -diabetic rats. Images were combined to matching endothelial marker (red), nucleus marker (blue) and eNOS florescence antibody (green) (A3, B3, C3 \& D3). Scale markers are $100 \mu \mathrm{m}$. 
As shown in Fig. 10, total eNOS immunofluorescence was significantly reduced in endothelial cells cultured from STZ -diabetic rats compared to eNOS immunofluorescence from endothelial cells cultured from control rats (Fig. 10A, $\mathrm{P}<0.001)$. eNOS immunofluorescence showed a significant increase when insulin treated STZ-diabetic endothelial cells were compared to untreated STZ-diabetic endothelial cells. (Fig. 10B, P<0.001).
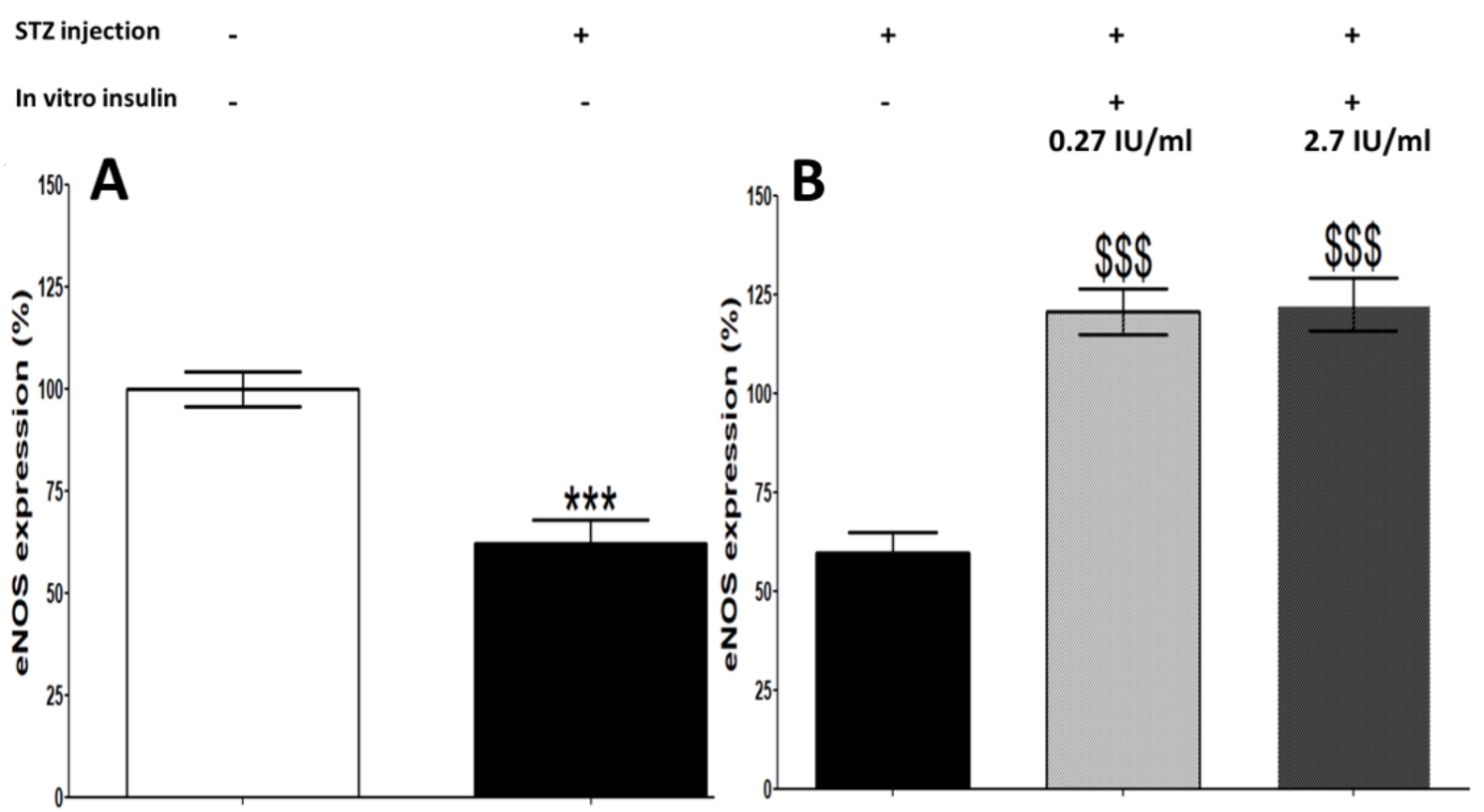

Fig. 10 Total Endothelial nitric oxide synthase (eNOS) expression in primary rat aortic endothelial cells from control and streptozotocin (STZ)-diabetic rats and the effect of insulin. eNOS expression in aortic endothelial cells cultured from STZ- diabetic rats was significantly reduced compared to control cells (STZ-diabetic $n=6$, control $n=5)(10 A)$. Aortic endothelial cells cultured from STZ diabetic rats treated with insulin showed a significant increase in eNOS expression (STZ-diabetic endothelial cells treated with $0.27 \mathrm{IU} / \mathrm{ml} \mathrm{n}=3$, STZdiabetic endothelial cells treated with $2.7 \mathrm{IU} / \mathrm{ml} n=3$, STZ-diabetic endothelial cells $n=3$ ) (10B). Data shown as average percentage \pm S.E.M. Significance is represented as $* * * P<0.001$ vs control endothelial cells, un-paired t-test; $\$ \$ \$ P<0.001$ vs STZ-diabetic rats, one-way ANOVA with Tukey post-hoc test. 


\section{Discussion}

In this study, STZ-induced hyperglycaemia was confirmed by glucose measurement in blood samples. Blood glucose concentration was the main diabetes marker as rats were considered diabetic when their blood glucose readings exceeded $16 \mathrm{mmol} / \mathrm{l}$ between days 27 post-STZ-injection. STZ was shown to induce hyperglycaemia (4-fold glucose increase) in 96\% of the STZ-injected rats by day 8-14 (Fig. 1). These findings were similar to what was reported in previous studies (Bagri et al., 2009; Shamsaldeen et al., 2018). STZ-induced diabetes resembles Type 1 Diabetes through blunting insulin secretion by inducing $\beta$-cell necrosis (Lenzen, 2008). STZ has specific beta cell toxicity because it is taken up by the beta cell Glut-2 glucose transporter. Once inside pancreatic $\beta$-cells, STZ alkylates DNA causing cell necrosis (Elsner et al., 2000).

STZ-treated diabetic rats showed significant endothelial dysfunction, 2 weeks after injecting STZ, as shown in Fig. 2. As a consequence of diabetes, endothelial dysfunction is a common complication where endothelium-dependent vasorelaxation is impaired (Dhar et al., 2010; Ruiter et al., 2012). Cholinergic vasorelaxation was significantly impaired in STZ diabetic aortic rings (Fig. 2A). These findings match a previous study's conclusion that vascular dysfunction of STZ-treated rats is attributed to impaired cholinergic-induced endothelium-dependent vasorelaxation (Fukao et al., 1997). Previous studies have revealed the dependence of the cholinergic-induced vasorelaxation on the endothelial NO pathway (Buxton et al., 1993; Lopacinska and Strosznajder, 2005). The deterioration in cholinergic endothelium function was in parallel with impaired TRPV4-induced vasorelaxation in both STZ diabetic aorta and mesenteric arteries (Fig. 2B-E). This cholinergic and TRPV4 impaired 
vasorelaxation is consistent with signal transduction through cholinergic receptors depending in part on TRPV4 channel activity.

Previous research showed a significant effect of the TRPV4 antagonist, HC-067047 $(1 \mu \mathrm{M})$ on acetylcholine-induced vasorelaxation in murine cerebral arteries (Zhang et al., 2009). Moreover, cholinergic and TRPV4 cascades might be connected through endothelial muscarinic receptor activated phospholipase-C (PLC) hydrolysis of phosphatidyl inositol $(4,5)$ bisphosphate (PIP2) into diacyl glycerol (DAG) and inositol $(1,4,5)$ trisphosphate (IP3). IP3 binds to its corresponding smooth ER receptors $\left(I P{ }_{3} R\right)$ to evoke $\mathrm{Ca}^{2+}$ release from cellular stores which can then activate TRPV4 (Clapham, 2003; Ying et al., 2014). Moreover, TRPV4 was also shown to be activated through the cholinergic downstream cascade components, DAG-activated PKC signalling (Rohacs and Nilius, 2007). Additionally, a TRPV4 mouse KO study revealed its essential role in cholinergic-mediated endothelium-dependent vasorelaxation through a novel mechanism that involves $\mathrm{Ca}^{2+}$ influx through endothelium derived factor (11, 12 EET)-activated TRPV4. This enhanced $\mathrm{Ca}^{2+}$ entry then opens $\mathrm{K}_{\mathrm{Ca}} 1.1$ channels to cause membrane hyperpolarization of VSMCs and thereby vasorelaxation (Earley et al., 2005; Freichel et al., 2005). As these mechanisms of vasorelaxation through $\mathrm{NO}$ and EDHF signalling are present in aorta and in resistance arteries and differences are explained by the relative contributions of these mechanisms, NO predominating in large arteries, we decided to use primary aortic endothelial cells for cellular studies.

Calcium imaging experiments showed that cellular TRPV4 channel function was reduced in the endothelial cells cultured from STZ diabetic rats (Fig. 3 and 4). This might be because of changes in individual channel function or might result from a reduction in the number of functional channels. Immunocytochemistry studies on primary endothelial cells 
were conducted to examine the expression levels of TRPV4 and hence throw light on the molecular mechanism of compromised TRPV4-induced vasorelaxation in STZ-diabetic rats. As shown in Fig. 5 and 6, total TRPV4 expression was reduced by approximately $50 \%$ and cellular distribution was disrupted in endothelial cells isolated from STZ-diabetic rats. These findings are consistent with those of Monaghan et al. (2015) that showed TRPV4 downregulation in microvascular endothelial cells from diabetic retina.

Caveolin-1 expression was investigated in parallel to TRPV4 in the primary cultures of aortic endothelial cells. Caveolae are lipid and protein rich invaginations found in endothelial cells providing a docking site for numerous receptors, ion channels and enzymes (Frank et al., 2003). Previous studies showed that caveolin-1 is an essential component in TRPV4-induced vasorelaxation through modulating TRPV4 membrane localisation (Saliez et al., 2008). Moreover, another study showed TRPV4 co-localisation with caveolin-1 and $\mathrm{K}_{\mathrm{Ca}} 2.3$ potassium channels in human endothelial cells (Fritz et al., 2015). In a recent study, we found that diabetes-induced lipolysis was associated with the degradation of caveolae and a reduction in eNOS expression (Shamsaldeen et al., 2018). Such a disruption in caveolae may reduce levels of caveolin-associated TRPV4, compromising vascular function.

Therefore, caveolin-1 expression was examined in endothelial cells from STZdiabetic rats. As shown in Fig. 7 and 8, caveolin-1 expression was significantly reduced by approximately $30 \%$ in STZ- diabetic aortic endothelial cells compared to control aortic endothelial cell cultures. These findings support a previous study conducted on diabetic kidneys that revealed significant reduction of caveolin-1 expression and eNOS downregulation when compared to non-diabetic kidneys (Komers et al., 2006). Additionally, caveolin-1 was co-localised with eNOS in bovine aortic endothelial cells (Wang et al., 2009). 
Therefore, further investigations on eNOS expression were conducted in parallel with TRPV4 and caveolin-1. eNOS expression was $50 \%$ lower in aortic endothelial cells from STZ -diabetic rats compared to control aortic endothelial cell cultures (Fig. 9 and 10). eNOS and caveolin-1 downregulation in aortic endothelial cells from STZ- diabetic rats might be attributed to the inhibition of phosphatidylinositol-4,5-bisphosphate 3-kinase (PI3K) /Akt pathway since the PI3K inhibitor, wortmannin has been shown to inhibit eNOS and caveolin-1 translocation to the plasma membrane (Wang et al., 2009).

STZ-diabetic aortic endothelial cell cultures were incubated with Insulin to investigate the reversibility of downregulation of TRPV4, caveolin-1 and eNOS as shown in Fig. 3, 5, 6B, 7, 8B, 9 and 10B. Primary aortic endothelial cells from STZ -diabetic rats, treated with insulin $(0.27$ and $2.7 \mathrm{IU} / \mathrm{ml}$ ) for 5 days, showed significant improvement in TRPV4 expression, distribution and function (Fig. 6B). Such improved TRPV4 expression and distribution was mirrored in changes in caveolin-1 (Fig. 7 and 8B) and eNOS expression (Fig. 9 and 10B). As described by Wang et al. (2009), insulin induces the PI3K/Akt pathway to stimulate eNOS and caveolin-1 translocation towards the plasma membrane. Moreover, insulin induces eNOS palmitoylation by Golgi palmitoyltransferase, an enzyme that catalyses eNOS and caveolin-1 acetylation and hence translocation toward the plasma membrane (Hernando et al., 2006). Additionally, eNOS palmitoylation increases targeting to plasmalemmal caveolin-1 by approximately 10 -fold, a process that is required to optimize eNOS activity and results in almost all eNOS activity being resident in the caveolar membrane fraction (Shaul et al., 1996).

The molecular mechanism of TRPV4 downregulation in diabetes is still unclear. TRPV4 N-linked mannose glycosylation in the endoplasmic reticulum is followed by complex 
TRPV4 protein glycosylation in the Golgi apparatus, and both are vital post-translational modification steps for channel maturity, membrane translocation and function (Lei et al., 2013). Deleting 837-838 residues of the TRPV4 c-terminus renders the channels immature and trapped in the endoplasmic reticulum resulting in reduced plasmalemmal TRPV4 (Lei et al., 2013). In STZ-diabetic rats' aortic endothelial cells, TRPV4 expression was decreased and seemed to be trapped in a region that was overlapped with the nucleus which might be the endoplasmic reticulum (Fig. 5b2 and 6b2). Additionally, TRPV4 downregulation might be exacerbated by the decreased caveolin-1 expression as other studies have revealed that TRPV4 co-localisation with caveolin-1 is essential for TRPV4 functions such as production of EDHF and vasorelaxation (Saliez et al., 2008; Serban et al., 2010). Similar to our findings , a previous study revealed that an alteration in caveolae integrity or caveolin-1 abundance may lead to endothelial dysfunction (Rath et al., 2009). These studies explain the importance of caveolin-1 and TRPV4 co-localisation to maintain the TRPV4-mediated $\mathrm{Ca}^{2+}$ influx required for vasorelaxation through EDHF and NO generation, and potassium channel activation (Inoue et al., 2009; Serban et al., 2010; Watanabe et al., 2008). Moreover, in our STZ-diabetic rats we observed a disruption of TRPV4 mediated increase in intracellular calcium in aortic endothelial cells (Fig. 3 and 4) where both TRPV4 and calveolin-1 expression are decreased. Such a significant reduction in calcium influx was associated with a reduction in TRPV4 expression (Fig. 5 and 6) and TRPV4-induced vasorelaxation (Fig. 2). This disruption of expression and function could both be reversed by in vitro treatment of the aortic endothelial cell cultures with insulin, consistent with a direct action of insulin on the endothelial cells. This is the first study to demonstrate that the reduced expression of TRPV4, eNOS and caveolin-1 and dysfunction of TRPV4 can be reversed through insulin treatment of STZ-diabetic aortic endothelial cells in culture. 


\section{Conclusion:}

To the best of our knowledge, this is the first study that examines endothelial dysfunction and the three endothelial signalling components, TRPV4, CAVEOLIN-1 and eNOS; together in a single type 1 diabetes model. Insulin treatment is effective in restoring the expression of these three endothelial signalling components and the function of TRPV4 in this diabetes model. This demonstrates specific and direct beneficial effects of insulin on endothelial function in insulin-dependent diabetes, independent of any change in glucose levels. The effectiveness of insulin in the restoration of expression and function these endothelial signalling components merits further exploration.

Authors' Contributions: Yousif A Shamsaldeen, Lisa A Lione and Christopher D Benham conceived and designed the experiments; Yousif A Shamsaldeen performed the experiments; Yousif A Shamsaldeen analyzed the data; Yousif A Shamsaldeen contributed reagents/materials/analysis tools; Yousif A Shamsaldeen, Lisa A Lione and Christopher D Benham wrote and proofread the paper.

Acknowledgements: This research did not receive any specific grant from funding agencies in the public, commercial, or not-for-profit sectors. The authors wish to thank Mr David Clarke and Ms Lena Pye for their valuable technical assistance.

Conflict of Interest: The authors declare that there is no conflict of interest associated with this publication. 


\section{Abbreviations}

Ka1.1 large-conductance calcium-activated potassium channels

EDHF endothelium derived hyperpolarization factor

eNOS endothelial nitric oxide synthase

SKca2.3 small conductance calcium-activated potassium channel

STZ

streptozotocin

TRP

transient receptor potential

DMEM Dulbecco's Modified Eagle Medium

BCA Bicinchoninic acid

ANOVA Analysis of variance

\section{References}

American Diabetes Association, 2012. Diagnosis and Classification of Diabetes Mellitus. Diabetes Care 35, S64-S71.

Bagher, P., Beleznai, T., Kansui, Y., Mitchell, R., Garland, C.J., Dora, K.A., 2012. Low intravascular pressure activates endothelial cell TRPV4 channels, local Ca2+ events, and IKCa channels, reducing arteriolar tone. PNAS 109, 18174-18179.

Bagri, P., Ali, M., Aeri, V., Bhowmik, M., Sultana, S., 2009. Antidiabetic effect of Punica granatum flowers: Effect on hyperlipidemia, pancreatic cells lipid peroxidation and antioxidant enzymes in experimental diabetes. Food and Chemical Toxicology 47, 50-54.

Battle, T., Arnal, J.F., Challah, M., Michel, J.B., 1994. Selective isolation of rat aortic wall layers and their cell types in culture-Application to converting enzyme activity measurement. Tissue and Cell 26, 943-955.

Baylie, R.L., Brayden, J.E., 2011. TRPV channels and vascular function. Acta Physiologica 203, 99-116. Buxton, I.L., Cheek, D.J., Eckman, D., Westfall, D.P., Sanders, K.M., Keef, K.D., 1993. NG-nitro Larginine methyl ester and other alkyl esters of arginine are muscarinic receptor antagonists. Circulation Research 72, 387-395. 
Chen, G., Suzuki, H., Weston, A.H., 1988. Acetylcholine releases endothelium-derived hyperpolarizing factor and EDRF from rat blood vessels. British journal of pharmacology 95, 11651174.

Cines, D.B., Pollak, E.S., Buck, C.A., Loscalzo, J., Zimmerman, G.A., McEver, R.P., Pober, J.S., Wick, T.M., Konkle, B.A., Schwartz, B.S., Barnathan, E.S., McCrae, K.R., Hug, B.A., Schmidt, A.M., Stern, D.M., 1998. Endothelial Cells in Physiology and in the Pathophysiology of Vascular Disorders. The Journal of The American Society of Hematology 91, 3527-3561.

Clapham, D.E., 2003. TRP channels as cellular sensors. Nature 426, 517-524.

Cohen, R.A., Weisbrod, R.M., Gericke, M., Yaghoubi, M., Bierl, C., Bolotina, V.M., 1999. Mechanism of nitric oxide-induced vasodilatation refilling of intracellular stores by sarcoplasmic reticulum $\mathrm{Ca} 2+$ ATPase and inhibition of store-operated Ca2+ influx. Circulation Research 84, 210-219.

Dainty, I., McGrath, J., Spedding, M., Templeton, A., 1990. The influence of the initial stretch and the agonist-induced tone on the effect of basal and stimulated release of EDRF. British journal of pharmacology 100, 767-773.

de la Garza-Rodea, A.S., Knaän-Shanzer, S., den Hartigh, J.D., Verhaegen, A.P.L., van Bekkum, D.W., 2010. Anomer-Equilibrated Streptozotocin Solution for the Induction of Experimental Diabetes in Mice (Mus musculus). J Am Assoc Lab Anim Sci. 49, 40-44.

Dhar, A., Dhar, I., Desai, K.M., Wu, L., 2010. Methylglyoxal scavengers attenuate endothelial dysfunction induced by methylglyoxal and high concentrations of glucose. British Journal of Pharmacology 161, 1843-1856.

Diabetes UK, 2012. NHS spending on diabetes 'to reach $\mathrm{f16.9}$ billion by 2035 '.

Ding, Y., Gonick, H.C., Vaziri, N.D., 2000. Lead promotes hydroxyl radical generation and lipid peroxidation in cultured aortic endothelial cells. Am J Hypertens 13, 552-555.

Dolman, D., Drndarski, S., Abbott, N.J., Rattray, M., 2004. Induction of aquaporin 1 but not aquaporin 4 messenger RNA in rat primary brain microvessel endothelial cells in culture. Journal of Neurochemistry 93, 825-833.

Dong, H., Waldron, G.J., Cole, W.C., Triggle, C.R., 1998. Roles of calcium-activated and voltage-gated delayed rectifier potassium channels in endothelium-dependent vasorelaxation of the rabbit middle cerebral artery. British journal of pharmacology 123, 821-832.

Dora, K.A., Hinton, J.M., Walker, S.D., Garland, C.J., 2000. An indirect influence of phenylephrine on the release of endothelium-derived vasodilators in rat small mesenteric artery. Br J Pharmacol. 129, 381-387.

Earley, S., Heppner, T.J., Nelson, M.T., Brayden, J.E., 2005. TRPV4 forms a novel Ca2+ signaling complex with ryanodine receptors and BKCa channels. Circulation Research 97, 1270-1279.

Earley, S., Pauyo, T., Drapp, R., Tavares, M.J., Liedtke, W., Brayden, J.E., 2009. TRPV4-dependent dilation of peripheral resistance arteries influences arterial pressure. American Journal of Physiology 297, H1096-H1102.

Elsner, M., Guldbakke, B., Tiedge, M., Munday, R., Lenzen, S., 2000. Relative importance of transport and alkylation for pancreatic beta-cell toxicity of streptozotocin. Diabetologia 43, 1528-1533.

Frank, P.G., Woodman, S.E., Park, D.S., Lisanti, M.P., 2003. Caveolin, Caveolae, and Endothelial Cell Function. Arteriosclerosis, Thrombosis, and Vascular Biology 23, 1161-1168.

Freichel, M., Vennekens, R., Olausson, J., Stolz, S., Philipp, S.E., Weißgerber, P., Flockerzi, V., 2005.

Functional role of TRPC proteins in native systems: implications from knockout and knock-down studies. the Journal of Physiology 567, 59-66.

Fritz, S.G., Kaistha, A., Kacik, M., Markert, S., Hofmeister, A., Busch, C., Bänfer, S., Jacob, R., Grgic, I., Hoyer, J., 2015. Evidence for functional and dynamic microcompartmentation of Cav-1/TRPV4/KCa in caveolae of endothelial cells. European Journal of Cell Biology 94, 391-400.

Fukao, M., Hattori, Y., Kanno, M., Sakuma, I., Kitabatake, A., 1997. Alterations in endotheliumdependent hyperpolarization and relaxation in mesenteric arteries from streptozotocin-induced diabetic rats. British Journal of Pharmacology 121, 1383-1391. 
Hernando, C.F., Fukata, M., Bernatchez, P.N., Fukata, Y., Lin, M.I., Bredt, D.S., Sessa, W.C., 2006. Identifi cation of Golgi-localized acyl transferases that palmitoylate and regulate endothelial nitric oxide synthase. JCB 174, 369-377.

Hex, N., Bartlett, C., Wright, D., Taylor, M., Varley, D., 2012. Estimating the current and future costs of Type 1 and Type 2 diabetes in the UK, including direct health costs and indirect societal and productivity costs. Diabetic Medicine 29, 855-862.

Huang, A., Sun, D., Smith, C.J., Connetta, J.A., Shesely, E.G., Koller, A., Kaley, G., 2000. In eNOS knockout mice skeletal muscle arteriolar dilation to acetylcholine is mediated by EDHF. American Journal of Physiology-Heart and Circulatory Physiology 278, H762-H768.

Huang, A.J., Manning, J.E., Bandak, T.M., Ratau, M.C., Hanser, K.R., Silverstein, S.C., 1993. Endothelial cell cytosolic free calcium regulates neutrophil migration across monolayers of endothelial cells. JCB $120,1371-1380$.

IDF, 2017. Diabetes Atlas.

Inoue, R., Jian, Z., Kawarabayashi, Y., 2009. Mechanosensitive TRP channels in cardiovascular pathophysiology. Pharmacology \& Therapeutics 123, 371-385.

Komers, R., Schutzer, W.E., Reed, J.F., Lindsley, J.N., Oyama, T.T., Buck, D.C., Mader, S.L., Anderson, S., 2006. Altered Endothelial Nitric Oxide Synthase Targeting and Conformation and Caveolin-1 Expression in the Diabetic Kidney. Diabetes 55, 1651-1659.

Kwan, H.Y., Huang, Y., Yao, X., 2007. TRP channels in endothelial function and dysfunction. Biochimica et Biophysica Acta 1772, 907-914.

Lei, L., Cao, X., Yang, F., Shi, D.J., Tng, Y.Q., Zheng, J., Wang, K.W., 2013. ATRPV4 Channel C-terminal Folding Recognition Domain Critical forTrafficking and Function. The Journal of Biological Chemistry 288, 10427-10439.

Lenzen, S., 2008. The Mechanisms of Alloxan and Streptozotocin-induced Diabetes. Diabetologia 52, 216-226.

Lin, M.I., Fulton, D., Babbitt, R., Fleming, I., Busse, R., Pritchard, K.A., Sessa, W.C., 2003.

Phosphorylation of threonine 497 in endothelial nitric-oxide synthase coordinates the coupling of Larginine metabolism to efficient nitric oxide production. Journal of Biological Chemistry 278, 4471944726.

Lopacinska, K.D., Strosznajder, J.B., 2005. Cyclic gmp metabolism and its role in brain physiology. Journal of physiology and pharmacology 56, 15-16.

Lüscher, T.F., Barton, M., 1997. Biology of the Endothelium. Clin. Cardiol. 20, II-3-II-10.

Ma, X., Cheng, K.T., Wong, C.O., O'Neild, R.G., Birnbaumer, L., Ambudkar, I.S., Yao, X., 2011.

Heteromeric TRPV4-C1 channels contribute to store-operated Ca2+ entry in vascular endothelial cells. Calcium Cell 50, 502-509.

Ma, X., Du, J., Zhang, P., Deng, J., Liu, J., Lam, F.F.Y., Li, R.A., Huang, Y., Jin, J., Yao, X., 2013.

Functional role of TRPV4-KCa2.3 signaling in vascular endothelial cells in normal and streptozotocininduced diabetic rats. Hypertension 62, 134-139.

Monaghan, K., McNaughten, J., McGahon, M.K., Kelly, C., Kyle, D., Yong, P.H., McGeown, J.G., Curtis, T.M., 2015. Hyperglycemia and Diabetes Downregulate the Functional Expression of TRPV4 Channels in Retinal Microvascular Endothelium. PLoS ONE 10, 1-16.

Murphy, M.E., Brayden, J.E., 1995a. Apamin-sensitive K+ channels mediate an endotheliumdependent hyperpolarization in rabbit mesenteric arteries. The Journal of Physiology 489, 723-734. Murphy, M.E., Brayden, J.E., 1995b. Nitric oxide hyperpolarizes rabbit mesenteric arteries via ATPsensitive potassium channels. The Journal of Physiology 486, 47-58.

Mustafa, S., Sharma, V., McNeill, J.H., 2009. Insulin resistance and endothelial dysfunction: are epoxyeicosatrienoic acids the link? Exp Clin Cardiol. 14, e41-e50.

Poulos, T.L., 2006. Soluble guanylate cyclase. Current Opinion in Structural Biology 16, 736-743.

Rath, G., Dessy, C., Feron, O., 2009. Caveolae, caveolin and controlof vascular tone: Nitric oxide (no) and endothelium derived hyperpolarizing factor (edhf) regulation. Journal of physiology and pharmacology 60, 105-109. 
Rohacs, T., Nilius, B., 2007. Regulation of transient receptor potential channels by phosphoinositides. Eur J Physiol 455, 157-168.

Ruiter, M.S., Van Golde, J.M., Schaper, N.C., Stehouwer, C.D., Huijberts, M.S., 2012. The role of methylglyoxal in hyperglycemia-induced impairments of vasoreactivity in rat saphenous artery, in: Ruiter, M.S. (Ed.), Reactivity, recruitment and remodeling of collateral arteries in diabetes. Gildeprint Drukkerijen, Amsterdam, pp. 83-98.

Saliez, J., Bouzin, C., Rath, G., Ghisdal, P., Desjardins, F., Rezzani, R., Rodella, L.F., Vriens, J., Nilius, B., Feron, O., Balligand, J.L., Dessy, C., 2008. Role of Caveolar Compartmentation in EndotheliumDerived Hyperpolarizing Factor-Mediated Relaxation. Circulation 117, 1065-1074.

Sandow, S.L., Hill, C.E., 2000. Incidence of myoendothelial gap junctions in the proximal and distal mesenteric arteries of the rat is suggestive of a role in endothelium-derived hyperpolarizing factormediated responses. Circulation Research 86, 341-346.

Serban, D.N., Nilius, B., Vanhoutte, P.M., 2010. The endothelial saga: the past, the present, the future. Eur J Physiol 459, 787-792.

Shamsaldeen, Y.A., Lione, L.A., Benham, C.D., 2015. Decrease in TRPV4 Expression in Vascular Endothelium from STZ Treated Rats is Reversed by Insulin Treatment., Annual BPS Meeting. pA2 online, Queen Elizabeth II Conference Centre London.

Shamsaldeen, Y.A., Ugur, R., Benham, C.D., Lione, L.A., 2018. Diabetic dyslipidaemia is associated with alterations in eNOS, caveolin-1, and endothelial dysfunction in streptozotocin treated rats.

Diabetes/metabolism research and reviews, e2995.

Shaul, P.W., Smart, E.J., Robinsoni, L.J., German, Z., Yuhanna, I.S., Ying, Y., Anderson, R.G.W., Micheli, T., 1996. Acylation Targets Endothelial Nitric-oxide Synthase to Plasmalemmal Caveola. The Journal of Biological Chemistry 271, 6518-6522.

Shimokawa, H., Yasutake, H., Fujii, K., Owada, M.K., Nakaike, R., Fukumoto, Y., Takayanagi, T., Nagao, T., Egashira, K., Fujishima, M., 1996. The importance of the hyperpolarizing mechanism increases as the vessel size decreases in endothelium-dependent relaxations in rat mesenteric circulation. Journal of cardiovascular pharmacology 28, 703-711.

Smith, P.A., Proks, P., Moorhouse, A., 1999. Direct effects of tolbutamide on mitochondrial function, intracellular Ca2+ and exocytosis in pancreatic b-cells. Eur J Physiol 437, 577-588.

Tabit, C.E., Chung, W.B., Hamburg, N.M., Vita, J.A., 2010. Endothelial dysfunction in diabetes mellitus: Molecular mechanisms and clinical implications. Rev Endocr Metab Disord 11, 61-74. van den Oever, I., A. M., Raterman, H.G., Nurmohamed, M.T., Simsek, S., 2010.

EndothelialDysfunction, Inflammation, andApoptosisin DiabetesMellitus. Mediators of inflammation 2010, 1-15.

Wang, H., Wang, A.X., Liu, Z., Chai, W., Barrett, E.J., 2009. The Trafficking/Interaction of eNOS and Caveolin-1 Induced by Insulin Modulates Endothelial Nitric Oxide Production. Molecular Endocrinology 23, 1613-1623.

Watanabe, H., Murakami, M., Ohba, T., Takahashi, Y., Ito, I., 2008. TRP channel and cardiovascular disease. Pharmacology \& Therapeutics 118, 337-351.

WHO, 2015. http://www.who.int/mediacentre/factsheets/fs317/en/

Widmann, M.D., Weintraub, N.L., Fudge, J.L., Brooks, L.A., Dellsperger, K.C., 1998. Cytochrome P-450 pathway in acetylcholine-induced canine coronary microvascular vasodilation in vivo. American Journal of Physiology-Heart and Circulatory Physiology 274, H283-H289.

Ying, W.Z., Aaron, K.J., Sanders, P.W., 2014. Sodium and potassium regulate endothelial phospholipase C- and Bmx. American Journal of Physiology - Renal Physiology 307, F58-F63.

Zhang, D.X., Mendoza, S.A., Bubolz, A.H., Mizuno, A., Ge, Z.D., Li, R., Warltier, D.C., Suzuki, M., Gutterman, D.D., 2009. Transient receptor potential vanilloid type 4-deficient mice exhibit impaired endothelium-dependent relaxation induced by acetylcholine in vitro and in vivo. Hypertension 53, 532-538. 
Zygmunt, P.M., Högestätt, E.D., 1996. Role of potassium channels in endothelium-dependent relaxation resistant to nitroarginine in the rat hepatic artery. British journal of pharmacology 117, 1600-1606. 